\title{
The Effect of 3D Interactive Models on Conceptual Learning
}

\author{
by \\ Julien Lemay \\ Baccalauréat ès arts spécialisé approfondi en psychologie, University of Ottawa, 2010 \\ A thesis submitted to the Faculty of Graduate and Postdoctoral Affairs in partial \\ fulfillment of the requirements for the degree of \\ Master of Arts \\ in \\ Psychology
}

Carleton University
Ottawa, Ontario

(C) 2013 Julien Lemay 


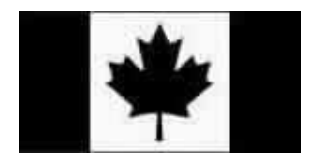

Library and Archives

Canada

Published Heritage

Branch

395 Wellington Street

Ottawa ON K1A 0N4

Canada
Bibliothèque et

Archives Canada

Direction du

Patrimoine de l'édition

395, rue Wellington

Ottawa ON K1A 0N4

Canada
Your file Votre référence

ISBN: 978-0-494-94673-2

Our file Notre référence

ISBN: 978-0-494-94673-2
NOTICE:

The author has granted a nonexclusive license allowing Library and Archives Canada to reproduce, publish, archive, preserve, conserve, communicate to the public by telecommunication or on the Internet, loan, distrbute and sell theses worldwide, for commercial or noncommercial purposes, in microform, paper, electronic and/or any other formats.

The author retains copyright ownership and moral rights in this thesis. Neither the thesis nor substantial extracts from it may be printed or otherwise reproduced without the author's permission.
AVIS:

L'auteur a accordé une licence non exclusive permettant à la Bibliothèque et Archives Canada de reproduire, publier, archiver, sauvegarder, conserver, transmettre au public par télécommunication ou par l'Internet, prêter, distribuer et vendre des thèses partout dans le monde, à des fins commerciales ou autres, sur support microforme, papier, électronique et/ou autres formats.

L'auteur conserve la propriété du droit d'auteur et des droits moraux qui protege cette thèse. $\mathrm{Ni}$ la thèse ni des extraits substantiels de celle-ci ne doivent être imprimés ou autrement reproduits sans son autorisation.
In compliance with the Canadian Privacy Act some supporting forms may have been removed from this thesis.

While these forms may be included in the document page count, their removal does not represent any loss of content from the thesis.
Conformément à la loi canadienne sur la protection de la vie privée, quelques formulaires secondaires ont été enlevés de cette thèse.

Bien que ces formulaires aient inclus dans la pagination, il n'y aura aucun contenu manquant. 


\begin{abstract}
The goal of the current study was to test the effect of a 3D interactive model on conceptual learning. Eighty-two participants were randomly assigned to a text with images, text with images and video, or text with images and $3 \mathrm{D}$ interactive model condition. In the end, after controlling for prior knowledge, and aptitude at learning, the 3D interactive model proved to be effective at improving conceptual learning. The 3D interactive model group scored almost two times higher than the text with images group on the conceptual post-test. The 3D interactive model group also showed a trend towards better performance than the video group, scoring nearly 1.5 times higher on the conceptual post-test.
\end{abstract}




\section{Acknowledgements}

I would like to thank Chris Herdman and Matthew Brown from the ACE lab for their support, guidance, and revisions; the support staff from the Psychology department, particularly Etelle Bourassa, for their administrative support and knowledge of procedures and deadlines; and Andrew Woo, Carl Byers, Jasper Li, and Thierry Crespo from NGRAIN Corporation for the material support provided through software licenses, technical support, technical training, as well as several hours of graphic design services. I would also like to acknowledge SurveyGizmo LLC for their free student licenses and technical support. Lastly, I would like to thank Claire Van Koughnett, my wonderful and supporting partner who helped me with countless hours of revisions and edits. 


\section{Table of Contents}

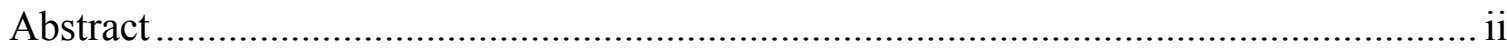

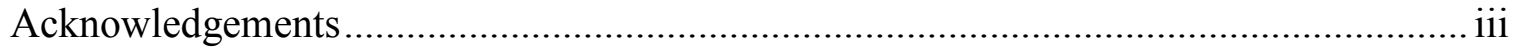

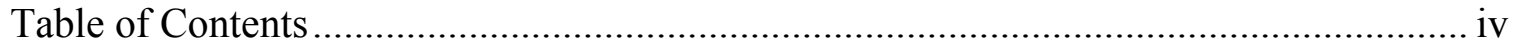

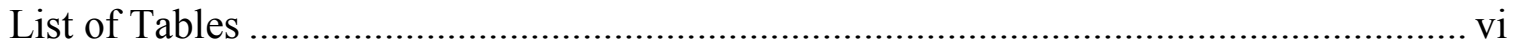

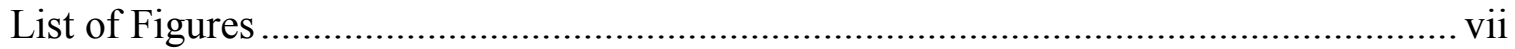

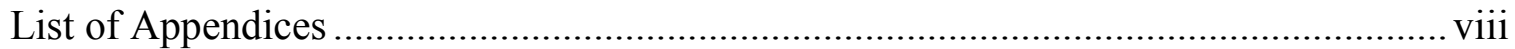

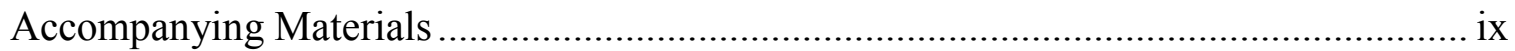

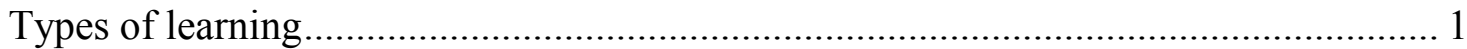

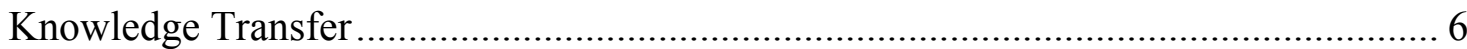

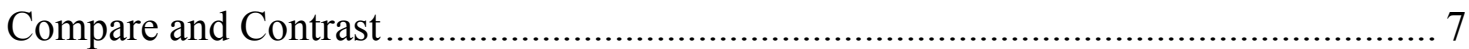

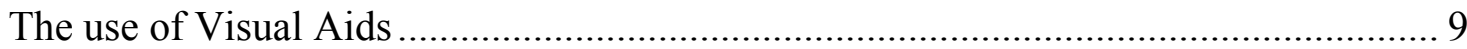

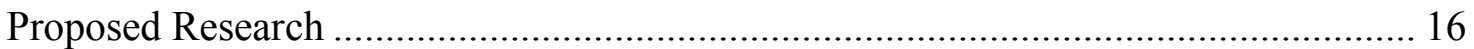

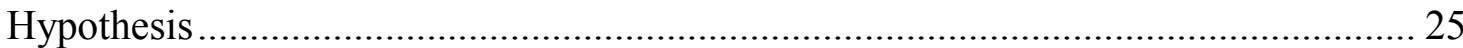

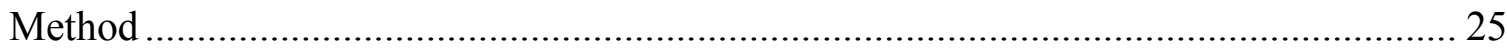

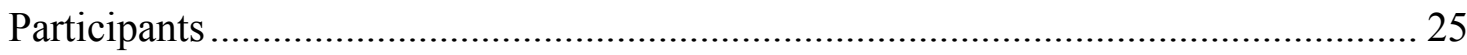

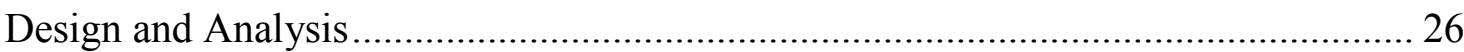

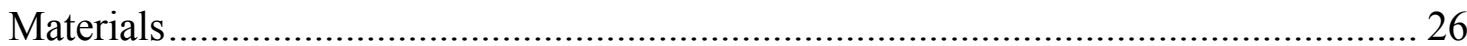

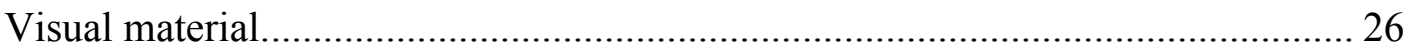

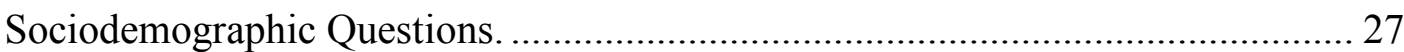

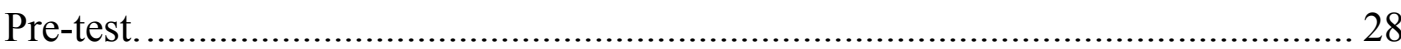

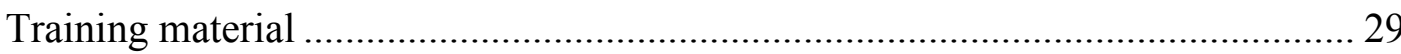

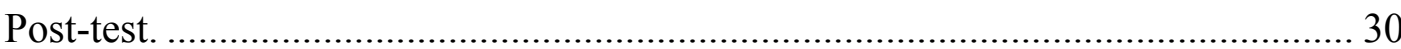

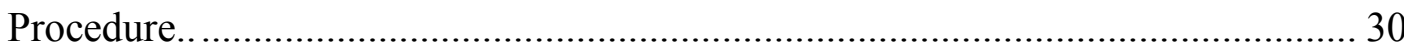

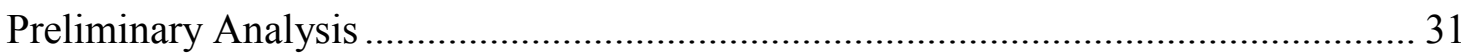

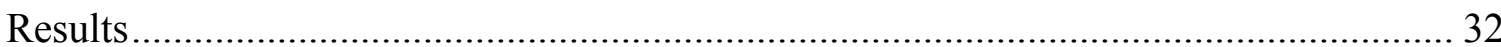

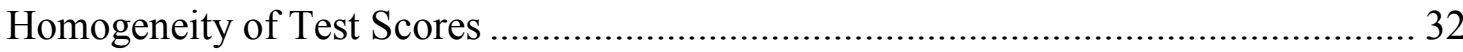

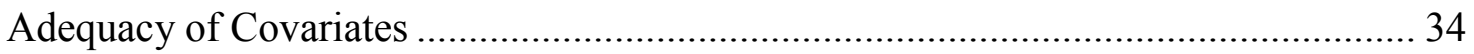

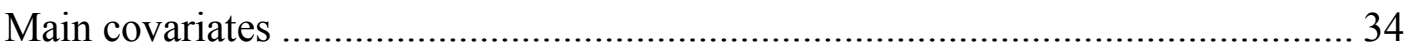

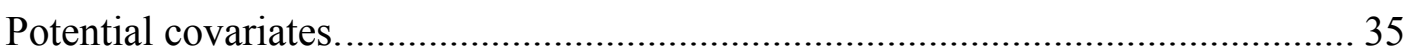

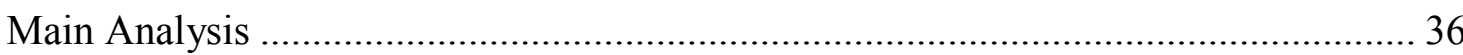

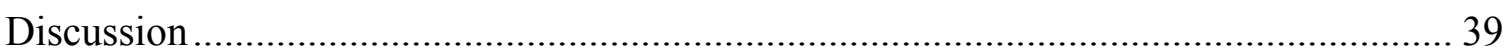

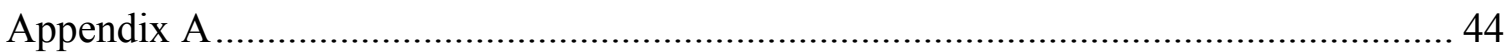




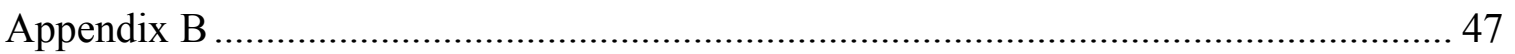

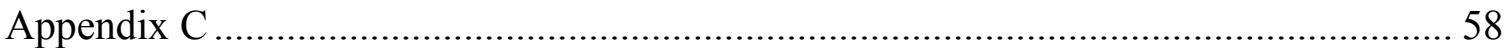

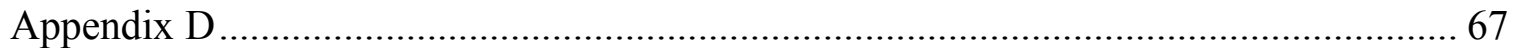




\section{List of Tables}

Table 1 List of questions in pre-test and post-test .................................................... 28

Table 2 List of questions in pre-test and post-test .................................................... 29

Table 3 Pre-Test Mean Scores in \% Correct …………............................................ 34

Table 4 Post-Test Mean Scores in \% Correct............................................................. 37

Table 5 Opinion about the method used ................................................................... 39 


\section{List of Figures}

Figure 1 Mean for Declarative Test Scores ............................................................... 33

Figure 2 Mean for Pre-Test Conceptual Test Scores .................................................. 34

Figure 3 Mean for Post-Test Conceptual Test Scores.................................................. 37 


\section{List of Appendices}

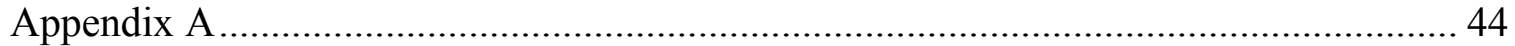

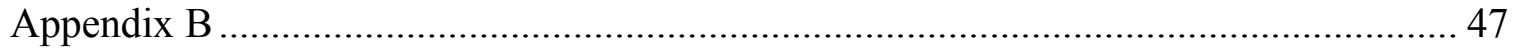

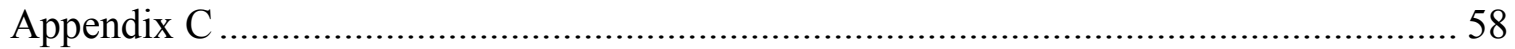

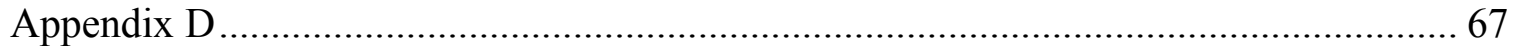




\section{Accompanying Materials}

CD: Videos, NGRAIN Viewer, and 3D Model 
The Effect of 3D Interactive Models on Conceptual Learning

Pairing images with text for explanatory purposes has been used since the $15^{\text {th }}$ century (Ferguson, 1977). Since then, videos, hyperlinks, sounds, and interactive 3D models have been introduced as methods of complementing text. It is often less expensive to use 3D models with interactive capabilities (henceforth referred to as 3D interactive models) than to use the actual object they represent for teaching purposes, especially if a large number of them are needed or if the object is expensive to build and/or acquire. A 3D interactive model can also allow for autodidactic learning by providing both information and practice without the need of an instructor. For these reasons, using 3D interactive models is of interest in research on how to improve teaching methods. The purpose of this thesis is to determine whether $3 \mathrm{D}$ interactive models provide a conceptual learning experience that is more effective than the traditional approach of supplementing text with images or with videos. The present research used photography, specifically the operation of a digital single lens reflex (digital SLR) camera, as the topic area in which conceptual learning was measured.

The use of a digital SLR camera's manual functions was the material to be learned in this research. The names of the knobs, dials, measurement units, etc., need to be learned declaratively, while the actual use of a function is a procedure and as such could eventually be stored in procedural memory. Finally, the application of the proper functions, especially in combination with one another, requires a conceptual understanding of the underlying factors: exposure and sharpness.

\section{Types of learning}


There are generally considered to be three types of learning: declarative, nondeclarative (which is composed of 6 subtypes of learning according to Squire, 2004), and conceptual. Most studies that have evaluated the impact of images and videos on learning focus on either procedural or declarative memory. Declarative memory is described by Cohen and Squire (1980) as memories that are available to conscious retrieval, and that relate to episodic, semantic, and working memory. The ability to detect and encode what is unique about a single perceptual event is at the core of declarative memory (Squire, 2004). For most scholastic purposes, declarative memory components, such as the episodic (what happened when) and semantic (definitions and facts) are the most immediately relevant aspects. Declarative memory tasks are normally passive, in the sense that they do not require any active or external interaction, but rather the absorption of information, and are often of a type such as one that requires the participant to listen to and repeat as many words as possible.

Non-declarative memory is defined by Cohen and Squire (1980) as "an experience induced change in behaviour". Although non-declarative memory and procedural memory are often wrongfully used interchangeably in the literature, procedural memory is a subset of non-declarative memory, which is used for skills and habits. The five other subtypes of non-declarative memory, all of which use distinct neural structures, are priming and perceptual learning, emotional classical conditioning, skeletal classical conditioning, and non-associative learning. Procedural memory is the subtype of non-declarative memory which is of most interest within the context of education (Squire, 2004). When needed for a cognitive or motor task, procedural memories are automatically retrieved and executed (Tunney, Taylor, Higbie, \& Haist, 
2001). An important aspect of a procedure is that it occurs over time (Bisanz \& LeFevre, 1990); in other words, a procedure is sequential in nature, it is a series of steps used to attain a goal.

Procedural memory is defined as being stored and used unconsciously, however it can be consciously recalled (Bisanz \& LeFevre, 1990). In the case where a procedure was properly acquired, we could assume that an individual would go through the steps in his or her head, and then be able to dictate or describe the steps. The problem is that this method of recollection (dictating or describing a properly acquired procedure) is difficult to externally discern from that of someone who has stored the procedure declaratively and has to recall each step as they go through the procedure. In a case where making the distinction between a procedural memory and a procedure that is stored declaratively is important, something such as time taken to recall the information could be an indicator of whether the procedure was completed using declarative or procedural memories, but this assumption in itself would have to be validated through research.

Unlike declarative memory tests, procedural tasks require the execution of a skill, such as when solving the Tower of Hanoi puzzle (Vakil, Hoffman, \& Myzliek, 1998) or the Tower of Toronto puzzle (Beaunieux et al., 2006), or when reading through a mirror (Squire, 2004). These tower tasks require participant to transfer a series of different sized disks from one peg to another in a specific sequence to solve the puzzle without violating certain rules (e.g., a larger disc can never be on top of a smaller disc), while the mirrored reading tasks require the eyes to move in an unusual direction. This planning of steps is the declarative component of a procedural task, but the automatic execution of the steps seems to be poorly addressed by experiments that use puzzles such as those described 
above (Beaunieux et al., 2006; Vakil et al., 1998). The only way for this kind of study to truly test procedural memory would be if there is a long delay (many days) between trials, and a lot of practice, in order to measure the actual use of procedural memory. It is complicated to completely separate declarative from non-declarative memory in order to obtain a pure measure of a single memory mechanism (Poldrack \& Foerde, 2008) without using amnesic patients (Squire, 2004). Indeed, it has been shown that there is a moderate positive relationship between some declarative memory tests and the ability to perform some procedural tasks (Tunney et al., 2001), as the two interact (Gregory Ashby \& Crossley, 2010). This is because all parallel forms of memory can influence each other in a healthy person (Squire, 2004).

Since a procedural task begins as a series of steps stored as declarative knowledge as it is being learned, and due to the short-term nature of this experiment, procedural tasks will henceforth refer to tasks that require a series of steps, but the criteria of automatic retrieval and execution cannot apply in this study, and the procedures will be assumed to be stored, and recalled, declaratively.

Conceptual learning, also known as concept learning, category learning, and concept attainment, is "the search for and listing of attributes that can be used to distinguish exemplars from non-exemplars of various categories" (Bruner, Goodnow, \& Austin, 1986). In other words, concepts allow us to group perceived elements into categories based on common pertinent traits. The learner compares and contrasts internal (memory-based) representations of perceptual objects (objects, events, feelings, thoughts, and abstract characteristics), which have been semantically grouped based on a number of featural dimensions, with instances/representations from different semantic categories 
that happen to contain common features. Conceptual learning differs from discriminating between objects, as discrimination is used in the creation of categories, but it does not provide a schema that allows for the classification of novel instances (Hoffman \& Rehder, 2010). When a concept is acquired, a label is created based on a generalization of a number of perceptual objects with common traits. This is why conceptual knowledge is described as being rich in relationships (Hiebert \& Lefevre, 1986). When a new percept is encountered, its traits are compared to the traits of the exemplars that form the category to determine whether or not the new percept belongs to the category. The more complex the concept, the harder it is to generate a concise set of rules to create a class or list of traits that define the category, leading to difficulties in teaching or learning the concept. According to Baroody and Ginsburg (1986) (as cited by Bisanz \& LeFevre, 1990), researchers can use the successful execution of a particular procedure to infer that a person possesses conceptual knowledge. Based on the idea that a procedure can be stored declaratively, especially in its early stages, this statement also implies that conceptual knowledge could be inferred from the correct application of declarative knowledge. Bisanz and LeFevre (1990) reaffirm this when they state that the level of conceptual knowledge acquisition can be inferred by evaluating the selective use of effective procedures under set conditions (i.e., knowing when to use the right procedure).

According to Hoffman and Rehder (2010), two assumptions have guided the study of concept learning since Hull (1920). The first is that "category learning amounts to learning to provide a common label for a set of objects." However, they state that few studies have examined how concepts arise from different kinds of learning tasks. They also mention that it is important to know how the representation formed in one learning 
task generalizes to other tasks. The second assumption they have identified is that “categories learned in one context transfer to another." However, Hoffman and Rehder (2010) note that the learner's ability to transfer knowledge across contexts requires a certain level of flexibility.

In a study on conceptual learning, Hoffman and Rehder (2010) used a supervised classification task, where researchers presented an image and waited for a response, after which they corrected the participant after every trial. Hoffman and Rehder, (2010) postulated that people may acquire categories in other ways than through the supervised classification. An example of this is feature inference learning, which involves predicting a missing feature based on the host of the feature being part of a category label. Participants are more successful in novel tasks when categories are learned via inference than when learned through supervised classification (Hoffman \& Rehder, 2010). This could be because participants are more sensitive to within-category than betweencategory similarities (Chin-Parker \& Ross, 2002). Conversely, participants who classify have worse performance than those who learn through inference, due to a narrower attention profile and learned inattention. This means that certain forms of learning structure imposed by experiments can hamper the ability to transfer knowledge.

\section{Knowledge Transfer}

Knowledge transfer refers to applying information learned in one context to another context. This specific definition of knowledge transfer is the way in which the term is generally used in the education literature, and differs from the common use of the term as a synonym for the term knowledge translation in some literature, which refers to 
the efficacy with which knowledge is shared. It is important to note that, in the present research, knowledge transfer is not synonymous with knowledge translation.

The purpose of this thesis is to evaluate how a teaching medium can impact or facilitate knowledge transfer. An underlying assumption here is that while creating conceptual links is a skill that can be improved, using better transmission methods can improve the creation of concepts without improving the underlying skill. In this study, knowledge transfer and conceptual knowledge will be evaluated using the same task. The reasoning behind this is that in order to be able to apply a method learned in one context to a structurally similar, yet different, context requires an understanding of the concept that binds these contexts. That is, the learner must acquire conceptual knowledge in order to be able to demonstrate successful knowledge transfer.

\section{Compare and Contrast}

In regions that score high in international standardized education evaluations such as Japan and Hong Kong, the preferred approach is to encourage students to discuss different potential solutions and compare them (Rittle-Johnson \& Star, 2007). There are many examples that support the idea that comparing and contrasting improves performance in certain learning tasks. In a study using multistep linear equations with seventh-grade students, Rittle-Johnson and Star (2007) found that comparing and contrasting improved the score for procedural knowledge and flexibility, as well as for conceptual knowledge. The students were classified as high-learning and modest-learning pairs. Unlike the modest-learning pairs, high-learning pairs were more likely to compare, and explore nonstandard solutions while taking efficiency into account. According to Rittle-Johnson and Star (2007), the improvement in procedural knowledge acquisition 
was due to comparing and contrasting as it encouraged students to explore alternative methods to solve the problems. Furthermore, students who compared could justify shortcut steps better than the students that did not compare, earning them a higher score on a measure of flexibility. Similarly, Gentner, Loewenstein, and Thompson (2003) found that students that compared problem solving solutions they were provided with showed a clear gain in a subsequent learning transfer task over those that did not compare solutions. In another experiment, one group of college students were presented two cases in a negotiation task and were asked to ponder the similarities. Compared to another group, who read the cases independently, this group transferred the negotiation solutions much more readily to a new case. Kurtz, Miao, and Gentner (2001) also reported that a participant's ability to find correspondences between two scenarios that depicted heat flow increased as the task demands to compare the two scenarios increased.

The benefits of comparing and contrasting to knowledge transfer manifest themselves early in life. Loewenstein and Gentner (2001) reported that children as young as 3-years old who were shown more than one hiding event performed significantly better when they were asked to find the hidden toy in a perceptually different room, so long as the hiding procedure followed the same rules. Even six-month olds show better category integration, as evidenced by longer looking times at other intra-category objects than at inter-category objects, when presented with multiple stimuli side by side rather than in series (Oakes \& Ribar, 2005).

The positive effects of comparing and contrasting in a learning task are higher when the comparisons are guided. For example, the simple suggestion of comparing and contrasting in the task instructions had a positive impact on score outcomes (Gentner et 
al., 2003; Kurtz et al., 2001). Catrambone and Holyoak (1989) found that the effect of comparing and contrasting on knowledge transfer required extensive directed comparison instructions.

The efficacy of comparing and contrasting also interacts with the level of prior knowledge. In a study by Star and Rittle-Johnson (2009), comparing mathematical estimation solutions, especially when presented side by side, improved the selection of an optimal solution. The authors demonstrated that in the acquisition of conceptual knowledge, comparing and contrasting interacted with prior knowledge, and was only beneficial to non-novices. Based on a review of other literature on comparing and contrasting, this interaction should be non-existent or have a very weak effect in simpler tasks.

\section{The use of Visual Aids}

Graphics, whether they are presented as still images or animations, change how individuals memorize information and improve the overall learning experience (ChanLin, 1996). There are multiple sources of evidence that demonstrate that visual aids improve various types of learning in different ways. However, different articles report varying effects and interactions. ChanLin $(1996 ; 1998)$ reported that graphics benefit descriptive tasks, especially in low prior knowledge individuals. Hegarty and Kriz (2008) (as cited by Ruiz, Cook, \& Levinson, 2009) reported that learners with low prior knowledge benefited more from animations than high prior knowledge learners because the animation explicitly depicted motion which the low prior knowledge learner would have had to otherwise infer. However, ChanLin (1998) reported that for procedural tasks, low prior knowledge groups did not benefit from visual aids, while high prior knowledge 
groups showed procedural memory improvements with still graphics, but not animated graphics. Mayer and Anderson (1992) demonstrated that inexperienced students were better at knowledge transfer when visual and verbal material was presented simultaneously in a driving task. Conversely, Reid and Beveridge (1990) found that graphics disrupted reading in less able students. However, the Reid and Beveridge's study is difficult to interpret because a text only control condition was not included, the only groups with a significant difference were post-hoc groups of the worst versus the best students, and it was assumed that looking at the images longer reduced scores. This conclusion is problematic because one could just as easily conclude that participants turned to the pictures for extra help because they were having trouble interpreting the text. Contrary to what ChanLin (1998) found, Large, Beheshti, Breuleux and Renaud (1996) (as cited by ChanLin, 1998) demonstrated that individuals benefited from animations in procedural tasks, more than in descriptive (or declarative) tasks, mirroring the comparative advantage that images produce in procedural versus declarative learning tasks. Lastly, concurrent speech combined with animation (Hasler, Kersten, \& Sweller, 2007) or graphics (Mayer \& Anderson, 1992) has been shown to be more effective than text in learning, and should be an integral part of an animation, as it provides temporal contiguity. The differences listed above on the effect of images on learning could be attributed to the type of learning, the type of diagrams used, the frequency of their use, the complexity of conveying information by using only a single type of instruction, and the relation between different types of learning, which are often not all taken into account together. The semantic transparency of the graphic being used to complement the text also has an impact on the learner, as it has been shown that visual aids with ambiguous 
meanings simply add a layer of complexity that can interfere with learning. Overall, the positive effect of images on learning seems to exist, yet it is often impaired by experiment design.

Cases where the learner must focus on two elements at once, such as text and images, for the information to be intelligible is referred to as the split attention effect (Ayres \& Sweller, 2005 as cited by Hasler et al., 2007). When two sources of information are dependant, such as having text that explains an animation, the cognitive load is increased. In other words, an animation that is self-explanatory should, in theory, be less strenuous to assimilate than one that is simpler but relies on accompanying text. There can also be a temporal split attention effect with animations, where earlier information is no longer physically available, but must be kept in working memory to be integrated with newer information. Although the efficacy of images in facilitating learning is often attributed to redundancy, it has been shown that, if unnecessary, redundancy may increase cognitive load (Kalyuga, Chandler, \& Sweller, 1999; Mayer \& Johnson, 2008; Yeung, Jin, \& Sweller, 1998). However, perceived redundancy can vary based on level of expertise. Low prior knowledge individuals may not see redundancy whereas high prior knowledge individuals do (Yeung et al., 1998). The effect of redundancy can also be perceived through a single or multiple sensory channels. That is, redundant information, when presented through different sensory channels, such as simultaneous speech and text presentation, increases retention and transfer (Adesope \& Nesbit, 2012). This happens because the text and speech do not interfere with each other at the sensory level if the reader can keep up with the pace. Lastly, pacing and segmentation can reduce cognitive load if the segments are meaningful, and the pacing is left to the learner (Moreno \& 
Valdez, 2005). Optimal learning occurs when attention is dedicated to the learning task at hand. This can be promoted by encouraging the learner to focus on the right information, and by reducing the presence of extraneous elements.

If a to-be-learned concept is too simple, any medium can lead to successful memorization, which can cause potentially misleading ceiling (null) effects. This claim is supported by Rieber $(1990 ; 1991 ; 1996)$ who demonstrated that when the complexity of the material to be learned was increased, animations accounted for an even larger difference in gains of tacit knowledge and gains in explicit understanding, compared to textual feedback. ChanLin (1998) reported that for descriptive material, in the low prior knowledge group, both participants with still graphics and those with animations performed better than the control. In the high prior knowledge group, only the animation group was better than the control. This indicates that the level of a learner's prior knowledge changes the threshold for what is considered to be a simple task.

The literature has ultimately failed to demonstrate that animations are superior to static media (i.e., images) (Bétrancourt \& Tversky, 2000 as cited by Hasler et al., 2007). That being said, as discussed above, the literature does generally indicate that visual aids improve learning performance. It has been postulated that the use of diagrams increases performance compared to text alone because the image completes information missing from the text (Glenberg \& Langston, 1992), and/or because it results in the information being presented twice (Fiore, Cuevas, \& Oser, 2003). A tentative explanation for both of these claims is that they rely on dual coding theory (Paivio, 1971 as cited by Fiore et al., 2003), which characterizes the processing of visual and auditory information as being independent, and states that the improvement in retention can be attributed to the 
simultaneous and independent encoding of both verbal and non-verbal information independently, which provides two separate memory traces that can be accessed during recall (Glenberg \& Langston, 1992). According to Fiore et al. (2003), dual coding theory does not stand as a comprehensive explanation because it implies that participants with diagrams should always outperform participants with text alone, regardless of the learning task at hand. This is not the case, as multiple studies have shown that diagrams had no effect on recognition or declarative knowledge tests. It is believed, however, that multi-coding holds its place, as the use of visual aids helps construct more elaborate representations of concepts (Glenberg \& Langston, 1992). These contradictions might stem from the verbal coding system using the visual processing apparatus. While reading text does stimulate the speech centers, just as auditory instructions would, it uses the visual pathway to get there. This means that visual working memory has to be split to process these two sources of visual input, resulting in attention being constantly diverted due to continuous scanning between the text and the images. The constant attentional shifting from the element in focus in turn creates a need to retain that information during the scanning so that reading or decoding of the image may resume when attention shifts back to that source. This would also support the fact that dual coding theory has reliably predicted outcomes when speech and images were used rather than text and images.

It has been theorized that visual aids are a form of analogical presentations of written information. The use of analogical information has proven to be effective in increasing retention (Gentner et al., 2003; Kurtz et al., 2001; Loewenstein \& Gentner, 2001; Oakes \& Ribar, 2005). When shown in tandem with the written material, the visual aids would facilitate the development of complex mental models (Gyselinck \& Tardieu, 
1999 as cited by Fiore et al., 2003). Similarly, Park and Gittelman (1992) found that animations were effective in illustrating complex structural, functional and procedural relationships among objects and events. It is highly probable that visual representations serve to reinforce the learning of information presented in text through redundancy and by complementing the text with new information. A third way that visual aids could improve performance is by directly providing a structure around which individuals can form a mental representation, or mental model of the information they are acquiring. This mental model would allow individuals to link information from different domains into one cohesive structure, arraying groups along properties (Glenberg \& Langston, 1992).

As mentioned above, the structure through which the information is presented could also be a factor in diverging outcomes in the literature. Fiore et al. (2003) studied the effect of diagrams in a complex learning task (learning to fly a plane). They found that participants performed significantly better in a condition where hypertext was accompanied by a diagram in an integrative knowledge (i.e., knowledge application) assessment test. However, there was no significant difference in a declarative knowledge assessment between the diagram and no diagram groups.

In a study by Brunye, Taylor, and Rapp (2008), students learned how to assemble toys using text-based, image-based, or image + text-based instructions. They were evaluated on order verification, recall, and object assembly tasks. In their first experiment, they compared performance on repetitious and complementary material, both of which were accompanied by the three instruction types. The image instruction and image + text instruction groups surpassed the text group in both free recall as well as in order verification, but there was no difference between the image + text group and image 
group in order verification. Repetitious presentation did generally provide learning benefits compared to complementary presentation. In their second experiment, Brunye et al. (2008) demonstrated that there was no difference between repetitious presentation and interleaved presentation (alternating image and text format) in the memory tasks.

Inference categorization works differently from rule-based categorization and each are useful in different contexts. According to Gregory Ashby and Crossley (2010), there are at least two separate category-learning systems that compete, either by inhibiting one another or by one completely denying access to the other, most likely by monopolizing a common necessary resource. These two systems produce what Gregory Ashby and Crossley (2010) called information-integration and rule-based categorization. Inference categorization works best when multiple stimuli are present in the creation of the schema, and is often difficult to verbalize (Ashby \& Gott, 1988). Meanwhile, rulebased categorization requires only a single stimulus to be identified, and is easily verbalized as it is associated with declarative knowledge (Gregory Ashby \& Crossley, 2010). In a sense, rule-based categorization is akin to supervised classification with respect to its explicitness. As mentioned before, explicit categorization lacks flexibility, and rule-based categorization would suffer from the same disadvantage in learning performance. However, rule-based categorization is more likely to be the starting point of the acquisition of a complex task or concept, as it allows the creation of a structure that can then facilitate information-integration. This is supported by evidence that low prior knowledge individuals are unable to properly focus their attention or sort the information into meaningful categories or concepts (Rieber \& Kini, 1995 as cited by ChanLin, 1998). In practice, these methods are used, and different levels of skills are acquired with each 
method. It is hypothesized here that low prior knowledge individuals would benefit most from rule-based categorization, while individuals with high prior knowledge would see more important improvements with inference categorization, as they should already know the rules. In sum, the simpler the concept, the more low prior knowledge individuals should improve with the use of inference categorization.

The use of $3 \mathrm{D}$ interactive models encompasses an interactive component. This interactive component allows for instantaneous visual feedback as the user manipulates the object. This in turn results in behavioural practice, which is effective for lower-level or declarative learning (Rieber, 1990). This interactivity is something that is inherent to interactive $3 \mathrm{D}$ models, but not to other mediums used to convey information to the learner, such as text, images, and videos. The interactive 3D model's instantaneous feedback allows learners to differentiate, often immediately, their intention from the actual outcome. This feedback is crucial for a simulation to be useful in an educational application (Norman, 1988 as cited by Rieber, 1996).

\section{Proposed Research}

A pre-test post-test design was used to test the impact of an interactive 3D model of a digital SLR camera on learning the basic concepts of exposure composition. Sociodemographic data, as well as the learner's baseline level of knowledge about photography was gathered in the pre-test session, prior to being exposed to the to-belearned material regarding the use and operation of the manual functions of a still-image camera. The material was presented in one of three forms as a between-subject manipulation: text with images, text with images and video, or text with images and the 3D interactive model. The post-test measured how much declarative knowledge was 
retained, what concepts were formed, and the participant's ability to transfer this knowledge. Performance on the declarative and conceptual pre-tests was used as a covariate to control for prior knowledge, and the declarative post-test was used as a covariate to control for basic acquisition and memorization skills, with the conceptual knowledge post-test as the outcome variable.

Increasingly complex visual aids (e.g., interactive 3D models) are being implemented more commonly as a result of the progression of technology. One effect of this progression of media technology is the use of hypertext to visually various pieces of information from disparate sources. The current research used a web-interface, which would have allowed the use of hypermedia in the configuration of the material. Although ultimately we chose to use a linear structure for the presentation of the information, the evolution of teaching technologies will invariably open the doors to the use of hypermedia. As such, it was necessary to acknowledge its potential use and the implications of the choice made. Hypermedia uses links that allow the learner to navigate through the information based on interest, and by necessity (following the path to the questions they have). This allows them to read a flow of information that matches their personal needs. Nonlinear hypermedia has been shown to improve an individual's understanding of how the facts they learn fit together (Eveland, Marton, \& Seo, 2004). In other words, nonlinear hypermedia promotes conceptual learning. Despite these reported learning advantages of using hypermedia, a linear learning structure will be used here. This is partially because nonlinear hypermedia structures have been shown to inhibit declarative learning compared to linear print (Tewksbury \& Althaus, 2000) or web-based material (Eveland \& Dunwoody, 2001). Nonlinear hypermedia was also shown to 
disadvantage low prior-knowledge and low working memory capacity individuals (DeStefano \& LeFevre, 2007). Given that the learning material in this experiment will be organized into only a few independent modules, the nonlinear model, which benefits the learner when multiple interconnected learning modules are used, would be unlikely to be of any great advantage here. Furthermore, the use of nonlinear hypermedia would add unnecessary variability (e.g., some pages not being read at all). Lastly, the interconnected, but not interdependent concepts will only be shown together once every concept has been explained individually.

The use of animations in teaching is another natural alternative with the progression of technology, and should therefore be discussed. The literature tends to demonstrate that animations have no benefit over static images, other than when the animation brings new information that was not presented with the images. The interactive 3D model, by its very nature, includes animation as the learner transitions between key frames. Further, using animation to explain large models can sometimes impair learning performance (Hegarty, Kriz, \& Cate, 2003). However, a still-image camera has very few mechanical components of significance in this context, and no complex mechanical systems and should therefore not be subject to the negative impact of animation-based learning. This means that the effect of animations should not yield any advantages or disadvantages over other learning methods.

Tversky, Bauer, and Betrancourt (2002) explained that the effect of animations (whether positive or negative) was due to the "congruence principle". According to this principle, when the presented media is close in nature to the internal representation, it helps in understanding the content. This media, however, can also be a still image. 
Another possible reason for the effects of animations is that they add a temporal dimension that would help if the material being taught had a temporal dimension to it, which is the case for all procedural tasks (although this temporal dimension may be insignificant if it is limited to the order of the steps). The use of the SLR camera does have a chain of steps, but the steps are not dependent on a temporal effect. That is, each step can take as much or as little time as possible without affecting the outcome. Another factor to take into consideration is the use of key frames with animations. Although it is possible to show too many images, the display of video/animation as well as static images was a more favorable condition than displaying images or video alone in Arguel and Jamet's (2009) study. However, the number of images remained an important moderator. As animations are sometimes overwhelming, the addition of still images could increase the risk of overwhelming the learner. Conversely, displaying key frames helps compensate for the transient nature of the animation (Arguel \& Jamet, 2009). The other element to consider in the use of animations, which can be applied to either the animation alone or the animation with key frames, is the ability to control the pace of information (Hasler et al., 2007; Ruiz et al., 2009). Although some would argue that the video controls would simply add an extra barrier, being able to control the flow of the information would reduce the risk of overwhelming the participant. Indeed, Hasler et al. (2007), showed that a group of learners with control over the video learned better than those without control over the pace. In other studies, this difference was only between the different animation levels, failing to demonstrate that animations with control over the pace are superior to still images (Ruiz et al., 2009). Furthermore, the improvement seen when interactivity with the animation was allowed (Ruiz et al., 2009) could be due to 
interactivity which engages the participant, and can be completely independent from the use of animations. Lastly, there is the use of speech in unison with animations (Hegarty et al., 2003; Kalyuga et al., 1999; Mayer, Hegarty, Mayer, \& Campbell, 2005; Ruiz et al., 2009), which respects the principles of temporal contiguity. However, Hegarty et al. (2003) have demonstrated that even when respecting all of these conditions, animations still failed to provide any benefit over still images.

It is hypothesized here that 3D interactive models bring a significant improvement to performance in procedural and knowledge-transfer tasks. Like in an animation, each transition between states of the model allows the learner to compare one state to the other, noting the relevant similarities and differences. However, unlike an animation, a 3D interactive model can be manipulated such that different states can easily be repeated as desired. This provides the learner with the opportunity to make dozens of comparisons over small time increments, without overwhelming them. Furthermore, Hegarty et al. (2003) concluded that learning is more effective if the learner is more active in the learning process, which is something that an interactive $3 \mathrm{D}$ model provides. The $3 \mathrm{D}$ interactive model forces the participant to focus on the relevant area of the animation, making the progression of the steps possible.

In order to equate the levels as much as possible, the images in the text with images condition are key frames from the 3D model, even though someone creating instructional text would not have access to such images unless they created a 3D model, at which point using a 3D interactive model or an animation would only be logical. In order to keep the levels as consistent as possible, the video in the video level was a screen capture of the $3 \mathrm{D}$ interactive model being put through its paces. 
In line with the limits of dual coding theory, it was not anticipated that declarative task scores would improve significantly as a result of the experimental manipulation. Further supporting our predictions is Vakil et al.'s (1998) work. According to Vakil et al. (1998), diagrams would result in interconnected knowledge and would increase conceptual relations, while declarative learning would not benefit from this use of visual aids.

As previously discussed, a design that includes repetition has both advantages and disadvantages for different levels of learners. Although repetition can disengage learners, we believed that this would not be a significant issue for us. We hypothesized that in the 3D interactive level, interactivity would keep the learner engaged. We expected that any potential advantage of having no repetition at all for the text only group would not affect the results. Although repetition violates the redundancy principle (Mayer et al., 2005; Mayer \& Johnson, 2008), it has also been shown that the use of key words when combined with speech and images was beneficial to learning (Mayer \& Johnson, 2008). A key conclusion of the paper was that "the challenge for instructional designers is to apply design principles in ways that reduce extraneous processing (such as scanning between captions and the graphic), manage intrinsic processing (such as attending to relevant portions of the narration and graphic), and foster generative processing (such as mentally organizing and integrating the material)." In the current study, interleaved information reduces scanning.

A potential issue with the $3 \mathrm{D}$ interactive model in the current research is if meaning is created by the participants (generative learning through a generative task), which would confound the effect of interactivity. Creating meaning rather than being 
given a meaning has been shown to improve learning. Even when learning is promoted by making students interact with the learning process (e.g., being able to pause, setting the steps of an explanation themselves), deep learning is not promoted unless feedback strategies are carefully taken into consideration (Moreno \& Valdez, 2005). The 3D model in this experiment differs from the type of interactivity used by Moreno and Valdez. Here, meaning will already be provided to the learner, but procedural steps will be practiced and corresponding effects of the manipulation will be displayed. Unlike the feedback used in Moreno and Valdez (2005), which allowed for guessing, participants here were not required to generate a concept on how to go through the steps of the procedure as the feedback was a walkthrough of the steps of the procedure. Therefore, the interactive 3D group did not benefit from being engaged in a supplementary generative processing task. This limited the effects of the 3D interactive model condition to interactive learning, by eliminating the generative component that is often paired with interactive learning tasks.

Since the use of visual aids is considered to be akin to analogical learning tasks, and because it has been shown that novices are more prone to an inert knowledge problem (i.e., the inability to retrieve appropriate knowledge) (Perfetto, Bransford, \& Franks, 1983 as cited by Gentner et al., 2003), individuals with higher prior knowledge ought to benefit most from comparing and contrasting, since they would have more complete recollections to compare. To address this issue, prior knowledge was controlled for.

When measuring performance on a procedural task, there can be a relationship with scores on a declarative memory test. The relationship between declarative memory 
tests and procedural tasks could stem from a learner overtly rehearsing (internally or externally) the steps of a task in order to perform a procedural task. Furthermore, the fact that some individuals rely more on procedural knowledge and some on conceptual knowledge changes the strength of that relationship for different tasks (Hallett, Nunes, \& Bryant, 2010). The stronger orientation towards procedural or conceptual knowledge should also impact the relationship between declarative knowledge and knowledge transfer, but this is outside of the scope of this study.

The subject matter area selected for study in this experiment is a Single Lens Reflex (SLR) camera. The SLR camera was chosen because it is a device with independent functions, but requires an understanding of all functions in order to be used proficiently. The functions are independent in that one does not need to understand all of them in order to understand one of them. Furthermore, the function modules can easily be explained physically (e.g., the shutter opens and closes), but the amount of light available is an abstraction that cannot be properly visualized without strong expertise. This makes the concept of the amount of light available, which links the camera's functions together, a concept that is harder to express declaratively. This provides a situation where declarative knowledge is linked by an inferred category or a concept. This means that evaluating the procedure for each function can depend on declarative knowledge, but properly combining the different functions and applying them in the right context depends on a conceptual understanding. This allows for the parsing of different types of learning under a single integrative task, rather than having wholly different tests for each type of learning. Had different tests for each type of learning been required, the potential effect of the variable complexity of the tasks, which potentially suit different types of 
learners, would have had to be taken into consideration. Moreover, prior knowledge would have had to be evaluated multiple times, and would have been harder to assess on traditional tasks such as the Tower of Hanoi.

Declarative learning was evaluated through declarative knowledge questions. The choice of answers contained the potentially correct answer: $\mathrm{P}$ (programmable), $\mathrm{S}$ (shutter), A (aperture) and M (manual) as well as bogus answers: ART (art) and SCN (scene) which are sometimes seen on cameras, but are usually related to filters that are overlaid on the photo (e.g., sepia colours), or focusing modes for impediments such as rain, rather than allowing to change the exposure composition. Participants were given a definition, and asked to select the word associated with this definition. Conceptual learning was evaluated through an application task. They were provided with an endresult (a photo) and asked how they would obtain this result. Since achieving the result required the correct declarative information and the correct procedure, and, at this stage, the procedural knowledge is still being held as declarative information, we controlled for the declarative scores in measuring the conceptual knowledge scores.

The images included in the text with images condition, and the camera model in the $3 \mathrm{D}$ interactive condition and the video condition provide limited information. None of these provided an actual outcome photo, thus preventing the learner from retaining the effects through short-term declarative memory. The visual material was limited to illustrating what was being explicitly mentioned in the text. As a result, the visual aspect of the training material was fairly impoverished compared to a normal training manual, which would include several chapters that discuss and illustrate what is being shown on a single page here. In all conditions, the training was a sequence of pages through which 
the participant navigated by clicking "next", in which text and images were presented in an interleaved fashion, with the 3D interactive model being in a separate section of the page.

\section{Hypothesis}

It was hypothesized that there would be no differences in the declarative knowledge tasks across the three conditions (text with images, text with video, text with 3D interactive model). It was further hypothesized that the $3 \mathrm{D}$ interactive model condition would yield significantly better conceptual learning than the text with images and video conditions, as indicated by performance on the post-test conceptual tasks.

\section{Method}

\section{Participants}

Eighty two participants were recruited from Carleton's SONA system. The participants were rewarded with a $1 \%$ course credit for participating in this 45 minute, inlab experiment. The text with images condition was comprised of 12 men and 16 women, with ages ranging from 18 to 40 . The 3D group was comprised of 10 men and 17 women, with ages ranging from 18 to 41 . The video group was comprised of 17 men and 10 women, with ages ranging from 18 to 52 . The experiment was of a pre-post test design, where both the pre- and post- sections were identical in content. The between subject factor was the testing level (text with images, text with images and video, text with images and 3D interactive model), while controlling for both declarative and conceptual pre-test scores, as well as post-test declarative scores. 


\section{Design and Analysis}

An ANCOVA was used instead of a change score test (such as repeated measure ANOVA), because it was the most appropriate analysis. One of the assumptions in most experimental models is that of regression towards the mean, and when this assumption holds (which it almost universally does), it is inappropriate to use a change score method (Allison, 1990). However, when this assumption is violated, change scores do become a viable option. Conveniently, as mathematically demonstrated by Kutner, Nachtsheim, Neter, and Li (2005), on pages 937-938 of their book "Applied Linear Statistical Models" the regression approach (using a covariate) gives the same outcome when the relationship between the two variables is of, or approaches, $\mathrm{r}= \pm 1$; something that would occur only when the regression towards the mean does not hold. Furthermore, difference scores normally lead to either inflated Type I or Type II error, and can cause issues of multicollinearity (Edwards, 2001). Lastly, it could easily be argued that if a change score approach was used when other covariates are to be added to the model, the $1: \pm 1$ relationship that supported the use of a change score analysis might in fact disappear when the other variables are added to the model. We can conclude that using a regression approach is incontestably the best way to proceed. The specific model we chose was an ANCOVA, as it allows us to regress the covariates on an ordinal independent variable.

\section{Materials}

Visual material. The 3D interactive model was a replica of a Nikon D40 SLR camera with a fictitious lens: a generic model of a lens was created rather than a copy of an existing lens. The iris was composed of 9 blades, pivoting on a central ring. There was no shutter or sensor in the model. Instead, a mirror was used to illustrate the function of a 
shutter, thus leading the participants to believe that the mirror plays the role of the shutter. The still frames, video, and interactive program were created using NGRAIN Inc. Producer 5 software (NGRAIN, 2012a). The training and experimental survey were administered through a web interface that required Internet Explorer 7 or above. The experiment was designed and administered through the SurveyGizmo's web interface software (SurveyGizmo, 2013). The 3D interactive model was embedded in the appropriate page using the NGRAIN Viewer plugin (NGRAIN, 2012b). The videos were embedded with YouTube (YouTube, 2013). The text with images condition, was comprised of text, followed by a screen capture of the 3D interactive model (on pages where the model was present), and a screen capture of the back of the camera to show the settings that were being discussed. The video condition was the same as the text with images condition, with the addition of a screen-captured video of the $3 \mathrm{D}$ interactive model. The 3D interactive model condition was the same as the text with images condition, with the addition of the 3D interactive model.

Sociodemographic Questions. The sociodemographic component was composed of 16 questions (see Appendix A; Table 1). There were four demographic questions, eleven questions to measure self-reported experience with cameras, one rating scale question about comfort level trying to use an SLR camera. 
Table $1 \quad$ List of questions in pre-test and post-test

\begin{tabular}{|c|c|c|}
\hline Category and type & Topic & $\begin{array}{c}\text { Total } \\
\text { number }\end{array}$ \\
\hline $\begin{array}{l}\text { Demographic questions: } \\
\text { drop-down list }\end{array}$ & Sex, age, education level, average grade & 4 \\
\hline $\begin{array}{l}\text { Self-reported experience } \\
\text { with cameras: Yes/no }\end{array}$ & $\begin{array}{l}\text { have you ever owned a film camera, a digital } \\
\text { camera, a film SLR, a DSLR }\end{array}$ & 4 \\
\hline $\begin{array}{l}\text { Self-reported experience } \\
\text { with cameras: rating } \\
\text { scale }\end{array}$ & $\begin{array}{l}\text { how savvy do you consider yourself with cameras, } \\
\text { do you use what you consider to be advanced } \\
\text { functions, how often do you manually change the } \\
\text { ISO/exposure/aperture/shutter/both the aperture and } \\
\text { shutter }\end{array}$ & 7 \\
\hline $\begin{array}{l}\text { Self-reported comfort } \\
\text { with cameras: rating } \\
\text { scale }\end{array}$ & Comfort using an SLR camera & 1 \\
\hline
\end{tabular}

Pre-test. The pre-test was composed of 15 questions (see Appendix B; Table 2).

There were eleven declarative knowledge questions, and four knowledge application questions (each composed of up to four sub questions) to measure the conceptual understanding of photo composition. As can be seen in Appendix B, the conceptual question section has more than four sub-questions per question, but only the appropriate elements would appear based on the answers given in the first and third part of the question. 
Table 2 List of questions in pre-test and post-test

\begin{tabular}{llc}
\hline \multicolumn{1}{c}{ Category and type } & \multicolumn{1}{c}{ Topic } & $\begin{array}{c}\text { Total } \\
\text { number }\end{array}$ \\
\hline $\begin{array}{l}\text { Declarative knowledge } \\
\text { questions: definition } \\
\text { word matching }\end{array}$ & $\begin{array}{l}\text { what do you call the amount of light allowed to } \\
\text { reach the sensor/ a measure of the aperture/ cover } \\
\text { that controls the amount of time light reaches the } \\
\text { sensor/ a range in the photograph within which the } \\
\text { image is in focus/ a measure of sensitivity of the } \\
\text { film or sensor/ opening of the iris }\end{array}$ & 6 \\
\hline $\begin{array}{l}\text { Declarative knowledge } \\
\text { questions: two choices }\end{array}$ & $\begin{array}{l}\text { which F-stop lets in more light, which F-stop has } \\
\text { the smallest depth of field, which shutter speed } \\
\text { leaves the shutter open longer, what does a higher }\end{array}$ & 5 \\
\hline $\begin{array}{l}\text { Knowledge application: } \\
\text { multiple choice }\end{array}$ & $\begin{array}{l}\text { Which setting would you use, what would this } \\
\text { setting change }\end{array}$ & 8 \\
\hline $\begin{array}{l}\text { Knowledge application: } \\
\text { two choices }\end{array}$ & $\begin{array}{l}\text { Would you increase or decrease the value of this } \\
\text { setting }\end{array}$ & 4 \\
\hline $\begin{array}{l}\text { Knowledge application: } \\
\text { open field }\end{array}$ & Why did you choose this option \\
\hline
\end{tabular}

The conceptual questions were based on the application of the basic concepts that were taught in the training material. The recognition of the effect seen in the photo tests participants' understanding of the concepts of sharpness/blurriness in relation to shutter speed and aperture. These questions also test whether structural links were formed between both desired and undesired blur, and what leads to them. The conceptual questions were purposely made to be very difficult in order to avoid a ceiling effect. Some of the perceived difficulty arises from the abstract nature of measuring light, which seems to be a very difficult concept to grasp for most people.

Training material. There were three training conditions. The first condition used a text with images tutorial on the use of manual camera functions. The tutorial covered exposure values, ISO level, F-Stop, flash, and shutter speed. It was comprised of explanatory text accompanied by images depicting the changes applied to the camera, (see Appendix C). The 3D interactive model condition consisted of a 3D interactive 
model to supplement the training material from the text with images condition. The 3D interactive model depicted some of the explored concepts as direct feedback to the actions applied to the camera. The first time participants encountered the 3D interactive model, they were instructed on how to interact with the 3D model. In each of the three uses of the 3D interactive model, a short animation depicting the changes that were applied to the camera was followed by the instruction to repeat what had just been observed, after which the physical effects of the action on the camera was shown. Lastly, the video condition consisted of the text with images condition, supplemented by a video, which was simply a screen capture of experimenter ideally using the 3D interactive model.

The tutorial also contained 5 questions to measure the level of proficiency. The level of knowledge being tested in these questions only required that the participant read the material, since the question was always on the same page as the paragraph containing the answer. Furthermore, the answer was usually the title of the paragraph. These 5 questions were repeated from the declarative knowledge pre-test, and were repeated again in the post-test.

Post-test. The tutorial was followed by a post-test. The post-test was identical to the pre-test, less the sociodemographic questions, with the addition of between three and five opinion questions on the use of the technologies at hand (see Appendix D).

Procedure. Participants took, on average, 27 minutes and 50 seconds $(\mathrm{SD}=8$ minutes 7 seconds). Upon their arrival, they were asked to read and sign the consent form. They were reassured that if they wanted to leave at any time, they were free to do so. The online survey was then opened for them, at which point they were told that if they 
had any questions they should feel free to ask the experimenter. The experimenter was present in the room, but had a desk that had its back to the participant and the experimenter read a book so that the participant would not feel intimidated. The experimenter did, however, keep an eye on the flow of the experiment to make sure that there were no issues. All participants had the same pre-test questions, but questions within a page and answers within questions were randomized by the software, when appropriate. Once at the training section, participants were presented with text and images, and, depending on their random assignment to the treatment groups, the text and images were followed by a video or the 3D interactive model. Following the pictures, the video, or the 3D interactive model, there was a proficiency question, if applicable. In the case of the 3D interactive model group, when the first model appeared, the experimenter would approach the student to ensure that they were not having any difficulty understanding how the software worked (given how novel it is to most individuals). Once the training was completed, the survey then flowed seamlessly to the post-test. It was identical to the pre-test in content, but was also randomized so as to not be identical to the pre-test. At the end of the post-test, subjective experience questions were added. Once the survey was completed, the experimenter then debriefed the participants, making sure that it was very clear that the test was intended to be very difficult, and that it was expected that the results would be very low.

\section{Preliminary Analysis}

Participants' proficiency scores were evaluated to ensure that they had read the material, or did not have severe reading comprehension difficulties. Predetermined criteria for the removal of participants were established through the use of proficiency 
questions. Participants had two chances to answer the question correctly, beyond which their performance was worse than random chance. The software immediately informed participants if they answered incorrectly, and they were directed to review material. Participants who responded incorrectly twice on two (or more) of the questions were automatically removed from the analysis without further investigation, resulting in the elimination of three participants. This threshold was chosen because it put them at the edge of chance-performance.

The pre-test scores between the text with images, video, and 3D interactive conditions were compared in order to ensure that there was proper randomization of the participants and that no unusual pattern occurred. The main analysis used an ANCOVA, with the post-test conceptual score as the dependent variable, and the pre-test declarative and conceptual scores as well as the post-test declarative score used as covariates. If there were a multicollinearity problem, which the tolerances would indicate, given the nature of the covariates, it would be possible to combine the pre-test variables.

\section{Results}

\section{Homogeneity of Test Scores}

A one way ANOVA was performed on the pre-test declarative score means (see Table 3) $\mathrm{F}(2,78)=1.456, \mathrm{p}=0.239$ (see Figure 1), and pre-test conceptual scores $\mathrm{F}(2,78)$ $=0.635, \mathrm{p}=0.533$ (see Figure 2), neither of which were statistically significant.

Next, the post-test declarative score was tested for differences using a one way ANCOVA. As predicted, there was no statistically significant difference between conditions after controlling for pre-test declarative scores $F(2,78)=1.752, p=0.126$ ( Figure 1). 
Figure 1 Mean for Declarative Test Scores

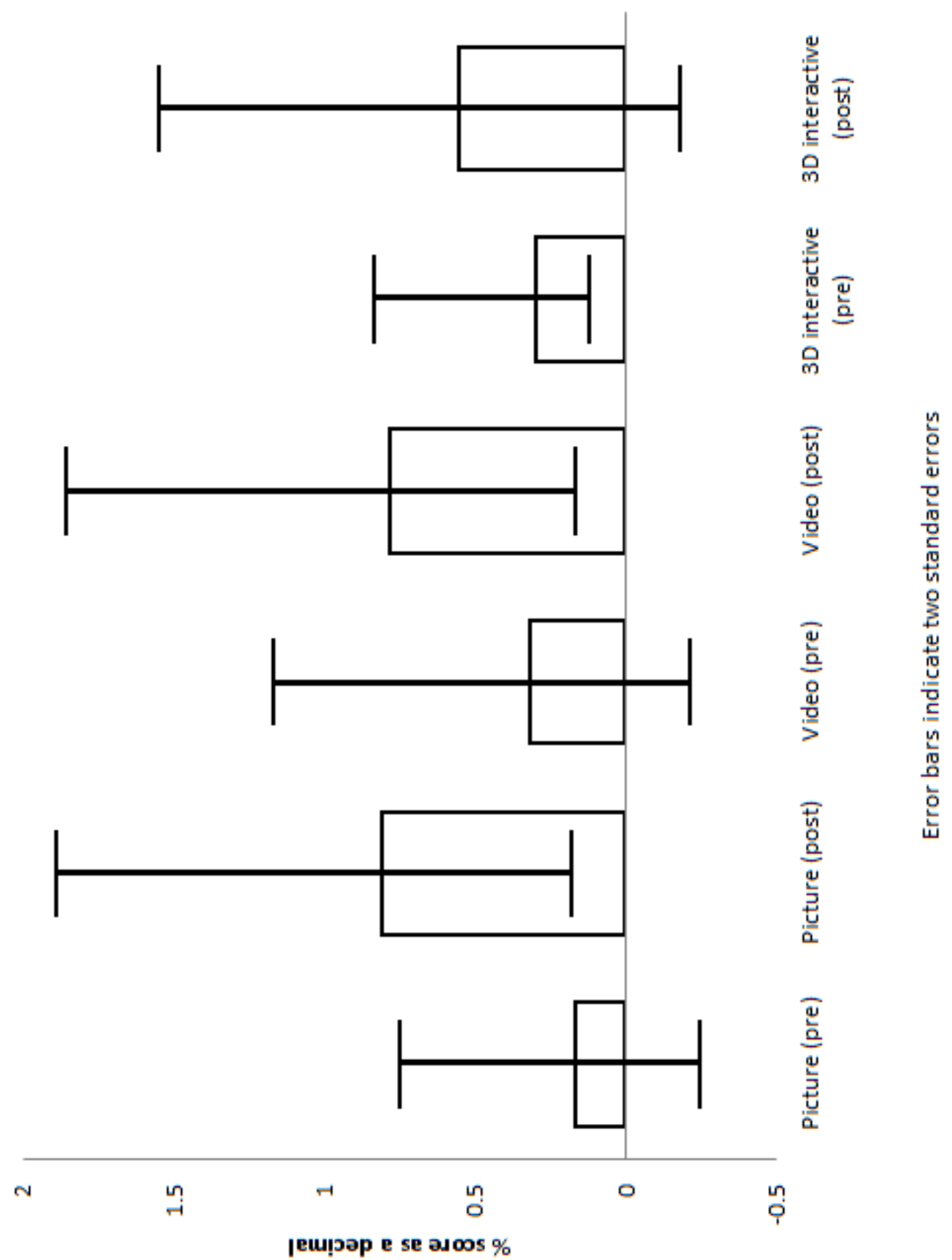


Figure 2 Mean for Pre-Test Conceptual Test Scores

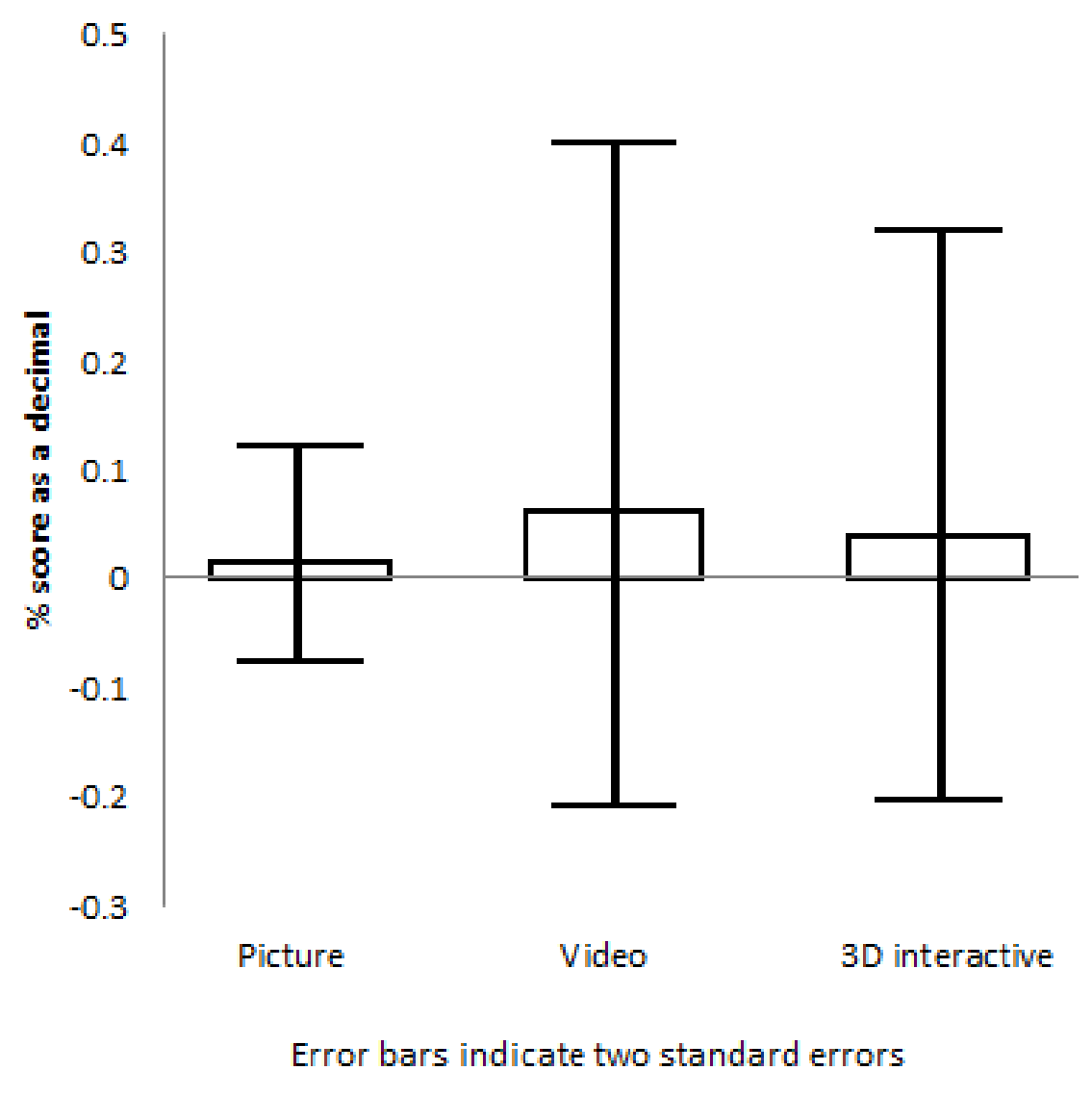

Table 3 Pre-Test Mean Scores in \% Correct

\begin{tabular}{lccc}
\hline & $\begin{array}{c}\text { Text with } \\
\text { images }\end{array}$ & Video & $\begin{array}{c}\text { 3D interactive } \\
\text { model }\end{array}$ \\
\hline Declarative Test (SD) & $0.1688(0.207)$ & $0.3182(0.266)$ & $0.1785(0.181)$ \\
Conceptual test (SD) & $0.0153(0.045)$ & $0.0632(0.136)$ & $0.0388(0.121)$ \\
\hline
\end{tabular}

\section{Adequacy of Covariates}

Main covariates. When testing for multicollinearity, the variance inflation factor (VIF) did not seem problematic for post-test declarative scores VIF $=1.305$, pre-test declarative scores VIF $=1.898$, or pre-test conceptual scores VIF $=1.580$, adding both pre-scores as covariates caused both pre-variables to become non-significant, while 
creating a statistically significant increase in R2 R2change $=0.115, \mathrm{~F}$ change $(2,78)=$ 10.984, $\mathrm{p}<0.001$. As a result, the pre-scores were combined into a single controlling variable. The pre-scores were standardized as a decimal expression of percentage, and added together.

Potential covariates. Self-reported prior experience with manual camera functions, as well time to completion of the experiment were also examined as potential covariates.

Self-reported prior experience was categorized as high if the participant responded above $50 \%$ and categorized as low if he/she responded below $50 \%$ on the prior experience questions. Self-reported prior experience with manual camera functions was not a significant predictor of the post-test conceptual score $F(2,75)=0.852, p=0.431$, nor did it interact with the treatment level $F(2,75)=0.170, p=0.844$. As such it was not included in the analysis.

The total time required to complete the experiment was analyzed. Time is an important factor in teaching tasks, and so it is important to note that it was not ignored; it was in fact explored and appropriately discarded as a covariate. There was no significant difference between groups, but there was a trend $F(2,79)=2.385, p=0.099$. However, when total time to completion was compared between the higher and lower scoring participants (using the $50^{\text {th }}$ percentile as a threshold) in a $3 \times 2$ ANOVA, this effect disappeared. The effect was attributable to lower scoring participants taking less time than higher scoring participants $F(1,76)=126.426, \mathrm{p}<0.001$, while the difference of time between groups was no longer significant $F(2,76)=0.385, p=0.682$, nor was the interaction between treatment level and high/low score $F(2,76)=0.093, p=0.912$. As 
such, if it had been used as a covariate, it would have violated the homogeneity of regression assumption, and washed out the results.

\section{Main Analysis}

The finalized model of the ANCOVA obtained through these aforementioned verifications showed that there was a statistically significant difference in the percentage of correct answers in the post-test conceptual questions between the treatment levels (see Table 4) $F(2,76)=3.696, p=0.029$, partial $\eta^{2}=0.089$ (see Figure 3 ). The covariates, pretest-scores $\mathrm{F}(2,76)=12.482, \mathrm{p}=0.001$, partial $\eta^{2}=0.141$ and post-test declarative scores $F(2,76)=16.783, p<0.001$, partial $\eta^{2}=0.181$ were both statistically significant. The total $\mathrm{R}^{2}$ and adjusted $\mathrm{R}^{2}$ for the model were of 0.494 , and 0.461 respectively. The Estimated marginal mean of the conceptual post-test for the text with images condition was $11.7 \% \mathrm{SE}=0.030,15.3 \% \mathrm{SE}=0.035$ for the video condition, and $22.7 \% \mathrm{SE}=0.029$ for the 3D interactive model condition. For the pairwise comparisons, Tukey's HSD was used. Due to software limitations, these had to be calculated manually and so did not have a corresponding p-value, only a critical threshold. Due to the lack of a linear relationship between a mean-difference and the p-value, the HSD was reported alongside an LSD pairwise comparison so that we can report an estimated p-value. The purpose of this is to provide a standardized and universally interpretable value to go along with the HSD. The HSD critical value was 0.0967 , based on $q(0.05,3,82)=3.375$. The difference between the $3 \mathrm{D}$ interactive model and the text with images groups was statistically significant at $0.110 \mathrm{SE}=0.041, \mathrm{p}=0.009$, while the difference between the $3 \mathrm{D}$ interactive model and video groups of $0.075 \mathrm{SE}=0.046, \mathrm{p}=0.106$ was only trending 
towards significance. The difference between the text with images and the video conditions was not significant, at $0.036 \mathrm{SE}=0.047, \mathrm{p}=0.447$.

\section{Figure 3 Mean for Post-Test Conceptual Test Scores}

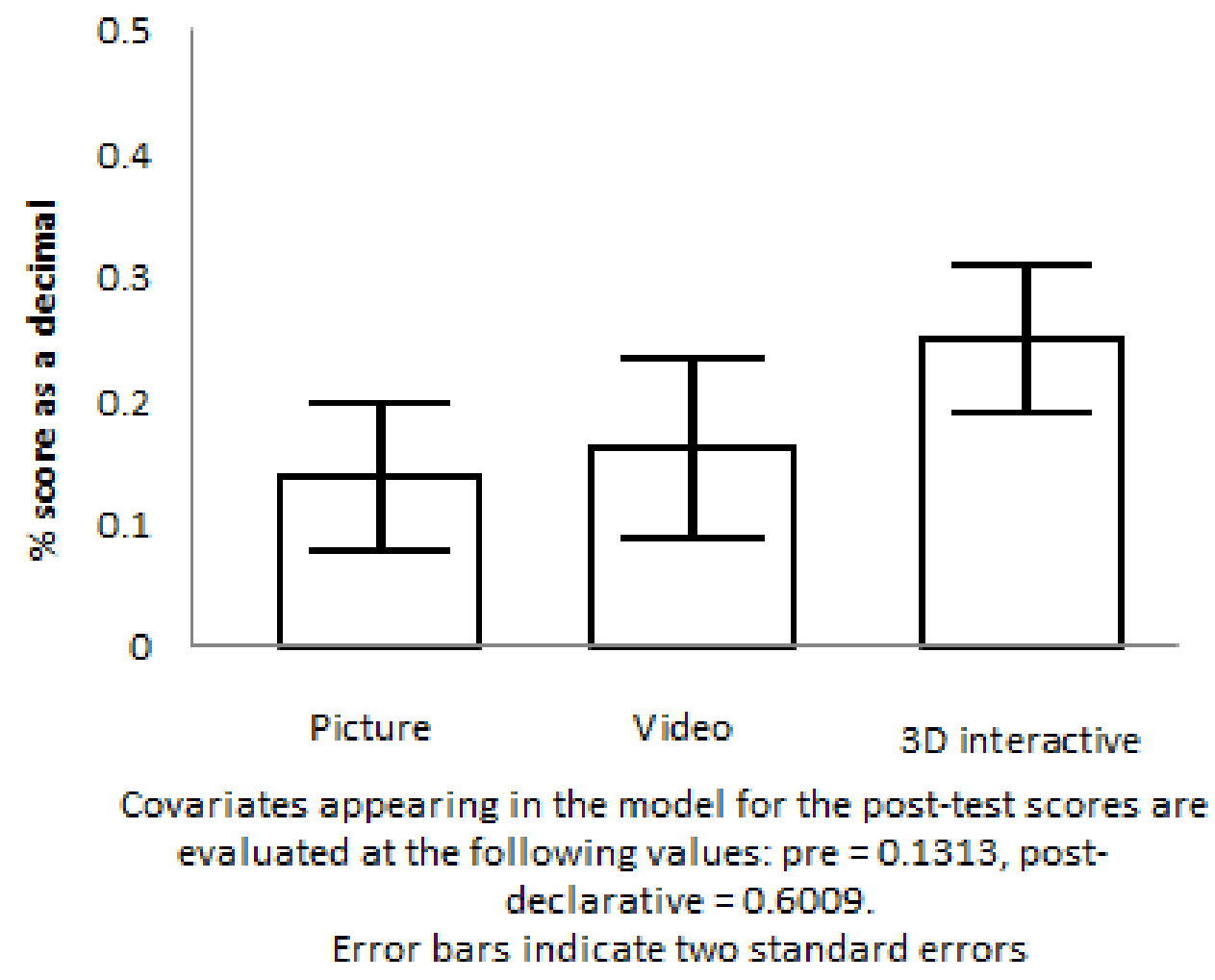

Table 4 Post-Test Mean Scores in \% Correct

\begin{tabular}{lccc}
\hline & $\begin{array}{c}\text { Text with } \\
\text { images }\end{array}$ & Video & $\begin{array}{c}\text { 3D interactive } \\
\text { model }\end{array}$ \\
\hline Declarative Test (SD) & $0.630(0.225)$ & $0.620(0.227)$ & $0.556(0.219)$ \\
Conceptual test (SD) & $0.138(0.030)$ & $0.161(0.036)$ & $0.248(0.030)$ \\
\hline
\end{tabular}

Most participants reported feeling more motivated when they had the 3D interactive model, but also thought that a video would have been equally useful. Meanwhile, only half of the participants who viewed the videos reported that they felt more motivated when using the video and almost all of the participants in the video group 
felt that a $3 \mathrm{D}$ interactive model would have been more useful and more motivating. The participants with neither the 3D interactive model nor the video reported feeling that a 3D interactive model would have been more motivating, but more than half thought that a video would have been equally useful in that respect (Table 5). This seems to indicate that participants who did not use the video fell for the same intuitive trap that has led so many researchers to try to demonstrate that videos are better than text and images. However, those who had been recently reminded of the video's relative uselessness by having used it and subsequently been tested on it overwhelmingly rejected the notion that it was equal to or better than a $3 \mathrm{D}$ interactive model. 
Table 5 Opinion about the method used

\begin{tabular}{|c|c|c|c|}
\hline & $\begin{array}{l}\text { Text with } \\
\text { images }\end{array}$ & Video & $\begin{array}{c}3 \mathrm{D} \\
\text { interactive } \\
\text { model }\end{array}$ \\
\hline $\begin{array}{l}\text { Did you think that the } 3 \mathrm{D} \text { model helped you } \\
\text { learn better? }\end{array}$ & & & $93 \%$ \\
\hline $\begin{array}{l}\text { Do you think that having a 3D interactive model } \\
\text { of a camera that showed how the camera works } \\
\text { like the video did, but allowed you to interact } \\
\text { with it, would have helped you learn better? }\end{array}$ & & $70 \%$ & \\
\hline $\begin{array}{l}\text { Do you think that having a 3D interactive model } \\
\text { of a camera that showed how the camera works } \\
\text { would have helped you learn better? }\end{array}$ & $89 \%$ & & \\
\hline $\begin{array}{l}\text { Do you think that an animation would help you } \\
\text { learn as much as a 3D interactive model? }\end{array}$ & & & $77 \%$ \\
\hline $\begin{array}{l}\text { Did you think that viewing the video helped you } \\
\text { learn better? }\end{array}$ & & $70 \%$ & \\
\hline $\begin{array}{l}\text { Do you think that the animation helped you learn } \\
\text { as much as a 3D interactive model could have? }\end{array}$ & $61 \%$ & & \\
\hline $\begin{array}{l}\text { Was using the } 3 \mathrm{D} \text { model more motivating than } \\
\text { reading the text? }\end{array}$ & & & $89 \%$ \\
\hline $\begin{array}{l}\text { Do you think using a 3D interactive model would } \\
\text { be more motivating than viewing the video? }\end{array}$ & & $81 \%$ & \\
\hline $\begin{array}{l}\text { Was viewing the video more motivating than } \\
\text { reading the text? }\end{array}$ & & $52 \%$ & \\
\hline $\begin{array}{l}\text { Do you think using a } 3 \mathrm{D} \text { model would be more } \\
\text { motivating than reading the text? }\end{array}$ & $89 \%$ & & \\
\hline Did you enjoy using the 3D model? & & & $89 \%$ \\
\hline $\begin{array}{l}\text { Would you want to use a 3D model again in the } \\
\text { future? }\end{array}$ & & & $93 \%$ \\
\hline Did you enjoy using the video? & & $51 \%$ & \\
\hline
\end{tabular}

\section{Discussion}

The effects on conceptual learning between the conditions demonstrated that the use of the 3D interactive model helps participants acquire concepts, without affecting declarative learning. The effect of the learning condition was independent of priorknowledge, which has been shown to be more important in declarative learning tasks. As expected, the treatment levels did not produce statistically significant differences in the 
declarative memory tests. However, participants in the 3D interactive group effectively performed almost twice as well as their text with images counterparts, and 1.5 times as well as their video group counterparts. Participants in the video condition did not learn more than those in the text with images condition. Because the content of the video and the 3D interactive models was identical, it can be concluded that the significant improvement rested on medium. Also, had the sample been larger (50 per group), assuming that the rest held constant (including the mean squared error), the Tukey's HSD would likely have been significant between the video and 3D interactive model groups, which already showed a trending difference.

Controlling for declarative knowledge, when testing for conceptual knowledge, was crucial. It is something that is not frequently seen in the literature, yet had a great impact on the analysis. Since many of the practices researched in education have a different impact on declarative, procedural, or conceptual learning, controlling for the other types of acquired knowledge should be done when possible, especially since it is impossible to have questions that are purely procedural or purely conceptual, while it is possible to have purely declarative questions. This means we can easily account for the declarative portion in a procedural or a conceptual test. Furthermore, in a case like this, where procedural learning was not a possibility due to the novelty of the material and the time constraints, it was possible to entirely isolate the conceptual component of the test through statistical means. In a case where there is procedural memory influence (i.e., where the learners may already be familiar with many of the methods at hand), a hierarchical regression would allow researchers to first partial out the declarative 
component from the procedural and conceptual components, and then partial out the procedural component from the conceptual one.

The use of a camera was chosen specifically because it could potentially benefit from the use of a 3D interactive model. Although the use of $3 \mathrm{D}$ interactive models is beneficial, as many concepts can be linked to visual representations, even simple math, it is hard to imagine how concepts that lack a clear physical application could benefit from the use of 3D interactive models. Fortunately, there are many topics that can benefit from this kind of tool. This relatively new educational tool has the potential to be widely used. Video, which has been plagued with mixed results in the literature, offers some similar benefits through dynamic visual representation. The NGRAIN software allowed us to overcome the major hurdles of video representation with relative ease. Many of the strategies identified in the literature to maximize the effectiveness of video are intrinsic to the $3 \mathrm{D}$ interactive model. The ability to control the pace is achieved through the need of user-input for the next step to take place. It is easy to repeat anything as needed since tasks are listed. Attention is inherently focused where it is wanted through not only the design (using arrows to illustrate), but also the requirement to interact with the pertinent components (as it would be impossible to interact with them without first identifying and focusing attention on them). Incidentally, these conclusions should also translate to any interactive feature, whether it is $3 \mathrm{D}$ or not. In this case, a camera shown in $2 \mathrm{D}$ would have become an abstract representation, but some simpler concepts do not require the added generation of a 3D model, and could capitalize on the interaction in a much simpler to program 2D environment (such as simple math, or simple plumbing). All of 
these aspects provide a learner-focused environment, rather than imposing the instructor's rhythm onto the learner.

The 3D interactive model engaged participants, and motivated them to pay attention to the material at hand. Those who used it also overwhelmingly preferred the 3D interactive model to the idea of a video. However, participants did not seem to believe that the 3D interactive model would improve learning to a greater extent than a video, unless they had seen the video, in which case they strongly felt that the $3 \mathrm{D}$ interactive model would have been superior. It is critical to note that $3 \mathrm{D}$ interactive models are thought to be equivalent to videos by non-experts. Given the popular misconception that videos are better than text with images, and equivalent to an interactive $3 \mathrm{D}$ model, the results supporting the advantage of $3 \mathrm{D}$ interactive models over text with images or videos should be distributed to educators and those who produce educational material. This education of the educators will be especially crucial as computer devices are becoming common in the classroom and educators and administrators are looking for ways to modernize the classroom. It would be important for them to know that they should use 3D interactive models before any further investment is made into non-interactive animated models.

It is also important to note that the purpose of this experiment was to compare text with images to a $3 \mathrm{D}$ interactive model as equally as possible. As such, the $3 \mathrm{D}$ interactive model did not fully leverage the potential of the technology at hand. For example, in the context of learning about camera functions, changing settings could have been accompanied with a live change in the properties of an outcome photo; something that would have required dozens, if not hundreds of labeled images in a traditional teaching 
medium. Yet, despite the fact that the 3D interactive model was not used to its full potential, performance was almost twice as good in the 3D interactive model condition as in the text with images condition.

In conclusion, the present research provides evidence that conceptual learning can be enhanced through the use of a 3D interactive model. The $3 \mathrm{D}$ interactive model that was implemented in the present research was relatively impoverished and did not fully exploit the capabilities of existing 3D interactive technologies. 3D interactive technologies continue to develop rapidly and are becoming increasingly available for use as teaching tools. Future research is required to fully understand the impact of these emerging technologies on knowledge acquisition. 


\section{Appendix A}

\section{Sociodemographic Questions}

\section{Demographics}

If there are any question you cannot answer or do not want to answer, feel free to skip them. Once you complete that page, you will receive a warning in case you missed it by accident.

Important: never use the backspace key or back button on your browser.

1) Sex:

( ) Male

( ) Female

( ) Other

2) Age:

3) Last attained level of education:

( ) Some high school

( ) Completed high school

( ) University studies (partial or complete)

( ) College studies (partial or complete)

( ) Post undergraduate studies (masters, PhD., law school, med school... partial or complete)

4) Average Grade

( ) $0-50 \%$

( ) $51-60 \%$

( ) $61-70 \%$

( ) $71-80 \%$

( ) $81-90 \%$

( ) $91-100 \%$ 


\section{Prior Knowledge}

5) Do you or have you ever owned a film camera

( ) Yes

( ) No

6) Do you or have you ever owned a digital camera (cellphone cameras count if you use it)

( ) Yes

( ) No

7) Do you or have you ever owned a SLR camera (film only)

( ) Yes

( ) No

( ) I don't know

8) Do you or have you ever owned a DSLR (Digital SLR)

( ) Yes

( ) No

( ) I don't know

9) How savvy do you consider yourself with cameras

( ) I know nothing about cameras

( ) I know very little about cameras

( ) I know a bit about cameras

( ) I know a lot about cameras

10) Do you consider that you use "advanced" functions with your camera

( ) I don't know what that is

( ) Never

( ) When needed

( ) Most of the time

11) How often do you manually change the ISO setting

( ) I don't know what that is

( ) Never

( ) When needed

( ) Most of the time

12) How often do you manually change the exposure value

( ) I don't know what that is

( ) Never

( ) When needed

( ) Most of the time

13) How often do you manually change the aperture

( ) I don't know what that is 

( ) Never
( ) When needed
( ) Most of the time
14) How often do you manually change the shutter speed
( ) I don't know what that is
( ) Never
( ) When needed
( ) Most of the time
15) How often do you manually change both the aperture value and shutter speed at the same time
() I don't know what that is
( ) Never
( ) When needed
( ) Most of the time 


\section{Appendix B}

Introduction and Pre-Test

\section{Pre-test declarative}

16) How comfortable would you feel to try to use an SLR camera.

( ) Not comfortable at all

( ) Not very comfortable

( ) Somewhat comfortable

( ) Very comfortable

17) What do you call:

The amount of light allowed to reach the film or sensor

( ) Exposure

() ISO setting

( ) Depth of Field

( ) Aperture

( ) Shutter

( ) F-stop

( ) I Don't Know

18) What do you call:

A measure of the aperture

( ) Exposure

() ISO setting

( ) Depth of Field

( ) Aperture

() Shutter

() F-stop

( ) I Don't Know

19) What do you call:

Cover that controls the amount of time light reaches the sensorlfilm

( ) Exposure

( ) ISO setting

( ) Depth of Field

( ) Aperture

() Shutter

( ) F-stop

( ) I Don't Know 
20) What do you call:

A range in the photograph within which the image is in focus

( ) Exposure

( ) ISO setting

( ) Depth of Field

( ) Aperture

( ) Shutter

( ) F-stop

( ) I Don't Know

21) What do you call:

A measure to the sensitivity of the film or sensor to light

( ) Exposure

( ) ISO setting

( ) Depth of Field

( ) Aperture

( ) Shutter

( ) F-stop

( ) I Don't Know

22) What do you call:

Opening of the iris

( ) Exposure

( ) ISO setting

( ) Depth of Field

( ) Aperture

( ) Shutter

( ) F-stop

( ) I Don't Know

23) Which F-Stop lets in more light

( ) $\mathrm{F} 5$

( ) F7

( ) I Don't Know

24) Which F-Stop will have the smallest depth of field

( ) $\mathrm{F} 5$

( ) F7

( ) I Don't Know

25) Which shutter speed leaves the shutter open longer

( ) 60

( ) 200

( ) I Don't Know

26) What does a higher ISO do 

( ) Amplify the signal
( ) Activate more pixels
( ) I Don't Know
27) Which ISO setting will have more noise
( ) ISO200
( ) ISO800
( ) I Don't Know 


\section{Knowledge application-Pre 1}

Please use the following picture when answering the question(s) on this page.

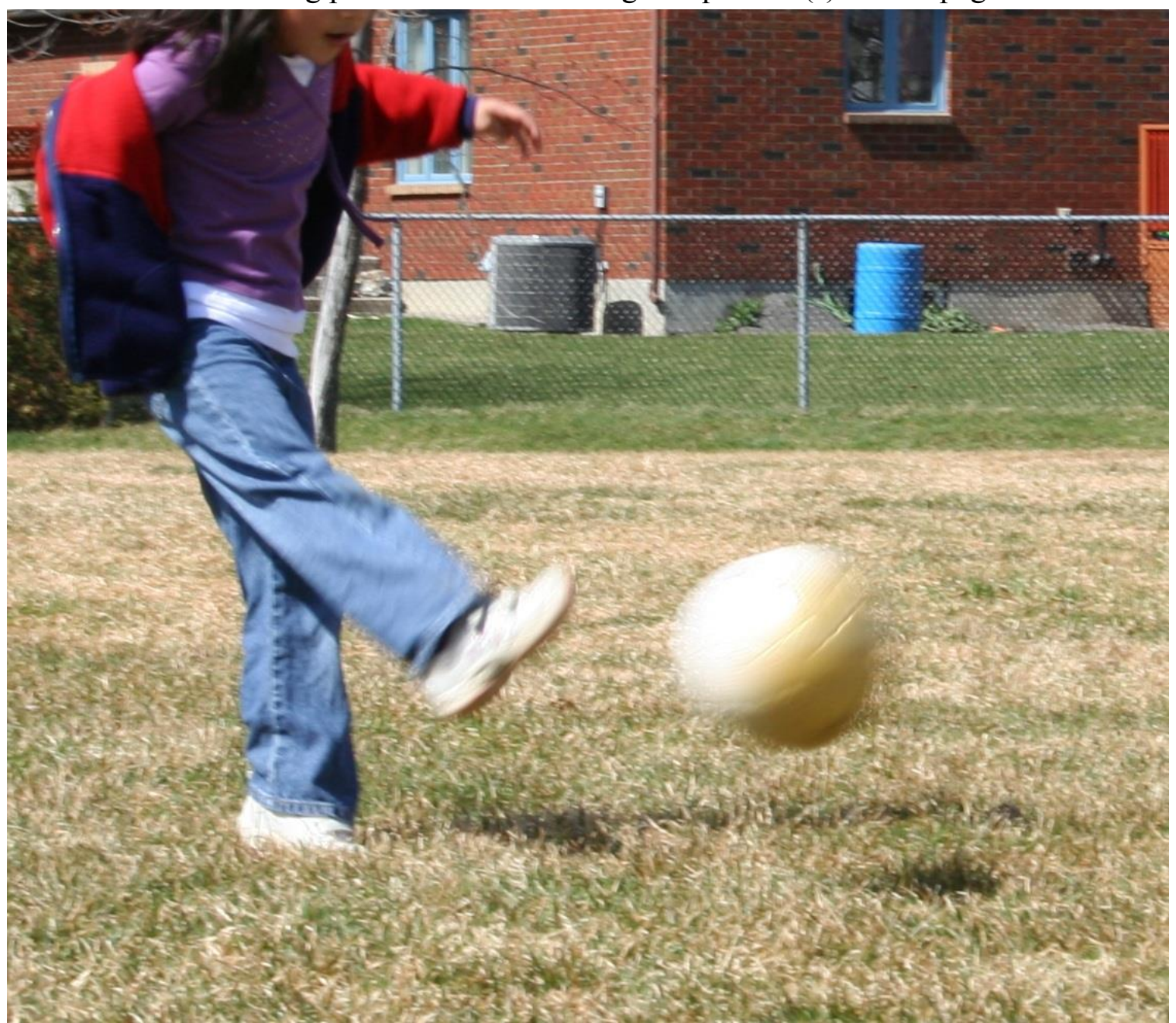

28) Select the function you would use to obtain the effect seen in the picture above, with the least possible changes.
( ) Auto
( ) $\mathrm{P}$
( ) A
() $\mathrm{S}$
( ) $\mathrm{M}$
( ) ART
( ) $\mathrm{SCN}$
( ) I don't know

29) Why did you chose this function. 
30) With this setting, what would you be changing.

( ) $\mathrm{EV}$

( ) F-Stop

( ) ISO

( ) Shutter speed

( ) Everything

( ) Flash

( ) I don't know

With this setting, what would you be changing.

[] EV

[ ] F-Stop

[ ] ISO

[ ] Shutter speed

[ ] Everything

[ ] Flash

[ ] I don't know

Would you increase or decrease the value of the setting you have chosen. Please name the functions you have chosen followed by what you would do with them.

31) Would you increase or decrease the value of the setting you have chosen.

( ) Increase

( ) Decrease

( ) Neither

( ) I don't know 


\section{Knowledge application-Pre 2}

Please use the following picture when answering the question(s) on this page.

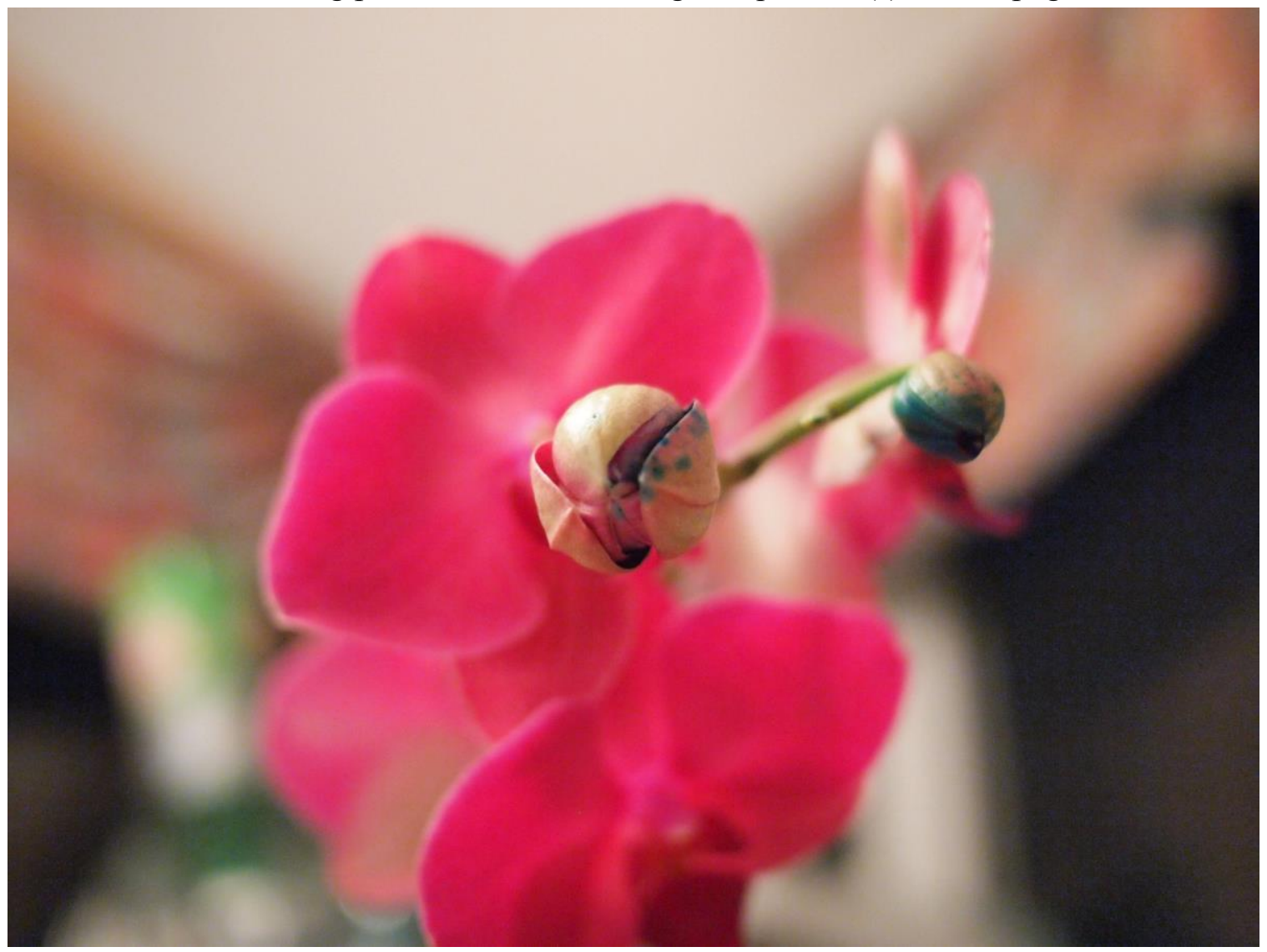

32) Select the function you would use to obtain the effect seen in the picture above, with the least possible changes.
( ) Auto
( ) $\mathrm{P}$
() A
( ) $\mathrm{S}$
( ) $\mathrm{M}$
( ) ART
( ) $\mathrm{SCN}$
( ) I don't know
33) Why did you chose this function. 
34) With this setting, what would you be changing.

( ) $\mathrm{EV}$

( ) F-Stop

( ) ISO

( ) Shutter speed

( ) Everything

( ) Flash

( ) I don't know

With this setting, what would you be changing.

[] EV

[ ] F-Stop

[ ] ISO

[ ] Shutter speed

[ ] Everything

[ ] Flash

[] I don't know

Would you increase or decrease the value of the setting you have chosen. Please name the functions you have chosen followed by what you would do with them.

35) Would you increase or decrease the value of the setting you have chosen.

( ) Increase

( ) Decrease

( ) Neither

( ) I don't know 


\section{Knowledge application-Pre 3}

Please use the following picture when answering the question(s) on this page.

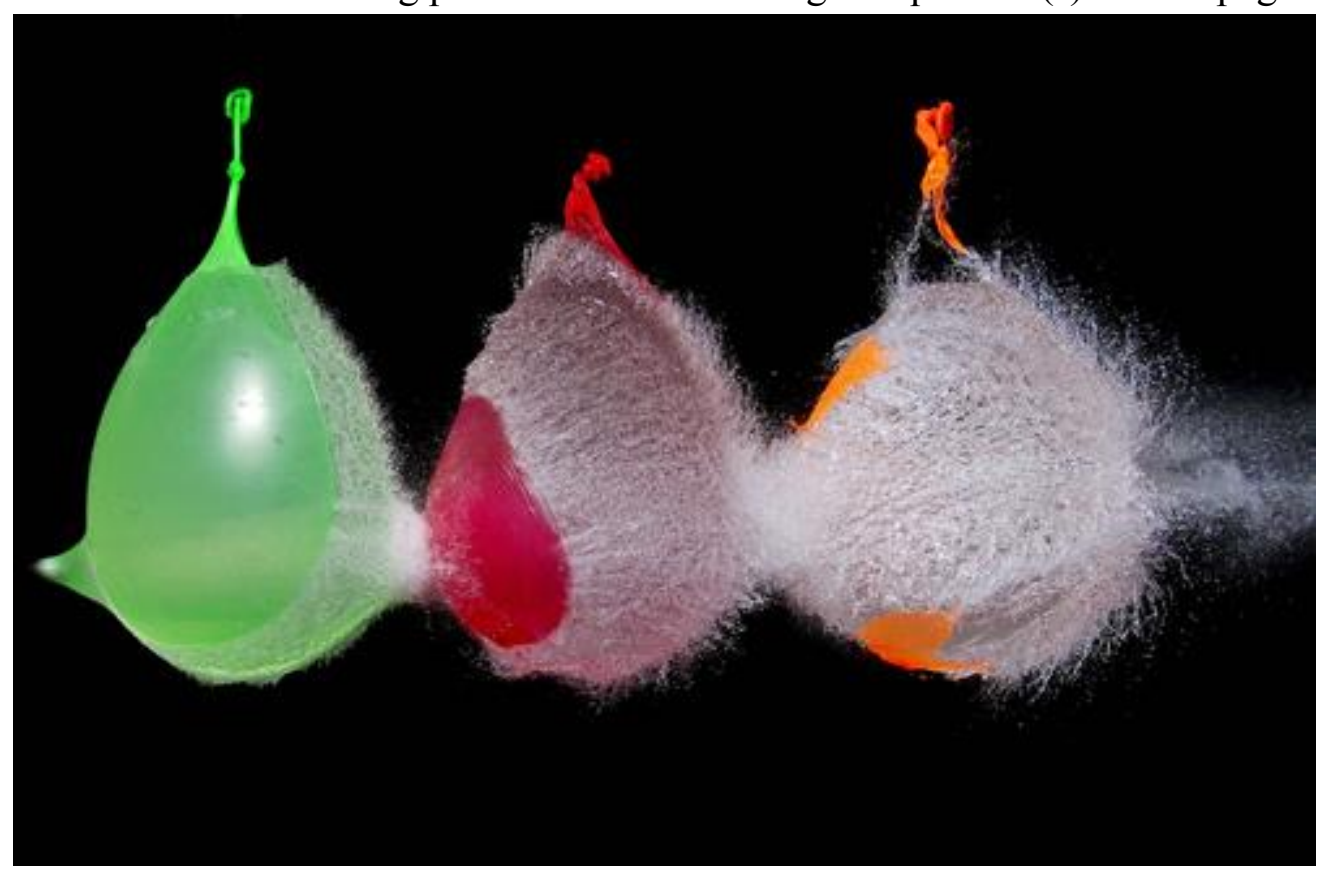

36) Select the function you would use to obtain the effect seen in the picture above, with the least possible changes.
( ) Auto
( ) $\mathrm{P}$
( ) $\mathrm{A}$
( ) $\mathrm{S}$
( ) $\mathrm{M}$
( ) ART
( ) $\mathrm{SCN}$
( ) I don't know

37) Why did you chose this function.

38) With this setting, what would you be changing.
( ) $\mathrm{EV}$
( ) F-Stop
( ) ISO
( ) Shutter speed
( ) Everything
( ) Flash
( ) I don't know 
With this setting, what would you be changing.

[] EV

[] F-Stop

[ ] ISO

[] Shutter speed

[] Everything

[] Flash

[] I don't know

Would you increase or decrease the value of the setting you have chosen. Please name the functions you have chosen followed by what you would do with them.

39) Would you increase or decrease the value of the setting you have chosen.

( ) Increase

() Decrease

( ) Neither

( ) I don't know 


\section{Knowledge application-Pre 4}

Please use the following picture when answering the question(s) on this page.

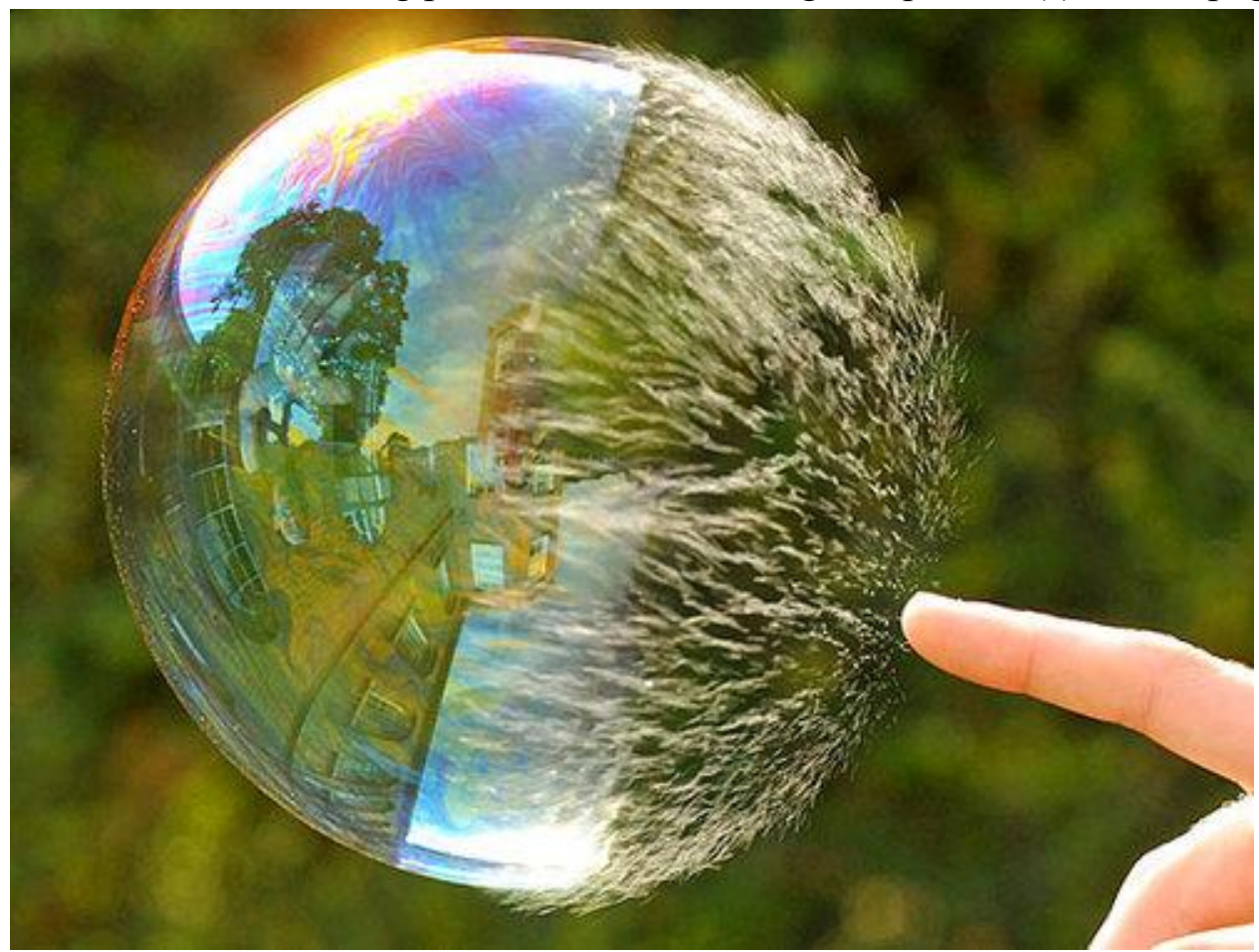

40) Select the function you would use to obtain the effect seen in the picture above, with the least possible changes.
( ) Auto
( ) $\mathrm{P}$
( ) A
( ) $\mathrm{S}$
( ) $\mathrm{M}$
( ) ART
( ) $\mathrm{SCN}$
( ) I don't know
41) Why did you chose this function.

42) With this setting, what would you be changing.
( ) $\mathrm{EV}$
( ) F-Stop
( ) ISO
( ) Shutter speed
( ) Everything
( ) Flash
( ) I don't know 
With this setting, what would you be changing.

[] EV

[] F-Stop

[ ] ISO

[] Shutter speed

[] Everything

[] Flash

[] I don't know

Would you increase or decrease the value of the setting you have chosen. Please name the functions you have chosen followed by what you would do with them.

43) Would you increase or decrease the value of the setting you have chosen.

( ) Increase

() Decrease

() Neither

( ) I don't know 


\title{
Appendix C
}

\author{
Tutorial
}

\section{Split}

Thank you, you have now completed the first half of the survey. You will now be directed to the tutorial, after which you will complete the survey.

\section{Intro}

You have now completed the preliminary questions, and are about to begin the tutorial portion. At the end of each section, you will be asked one question; you must answer the question correctly to move on. After this, you will be tested on what you have just learned.

Cameras have come a long way and automatic settings can help us take good pictures in a fraction of a second. But sometimes we have specific goals different from that of the camera's automatic system, or the automatic system is simply not complex enough to deal with a setup. This is why all SLR's (Single Lens Reflex) and many point and shoot (characterized by the fixed lens that cannot be removed) have manual settings that can be used to override the automatic system's choice of settings. The goal of the following is to teach you, in a very short and easy form, how to use those settings on a basic level, allowing you to cope with about $95 \%$ of situations you could encounter (with a bit of practice of course).

\section{Exposure Level}

Exposure level and Exposure value:

The most basic thing to keep in mind when taking pictures is that the entire camera revolves around light. The measure of the amount of light that goes to the film or sensor is called the "exposure" level. This exposure is counted in "exposure value" (EV), an exponential scale. As such, if your exposure meter indicates that you have an extra EV, it means you have twice as much light as you had at 0 . At two EV, you have twice as much light as at one EV and 4 times as much as at 0, etc. Exposure can be used two ways. You can either look at the exposure meter to see how much light is coming in, or you can set the exposure at a desired level and the automatic system will aim to get that much light in. Both are normally displayed on the same scale where an indicator shows a set value on top (if you set one) and little bars under the scale show a reading of how much light is coming in. In some cases, you can also get a numerical display of your setting. An exposure of 0 is a normal photograph and the default for just about any camera you have ever used.

In order to change the exposure alone: 
First turn the top dial to P, S, A or M

Now press the $+/$ - button and spin the wheel on the back of the camera

To the right to increase the value

To the left to decrease the value
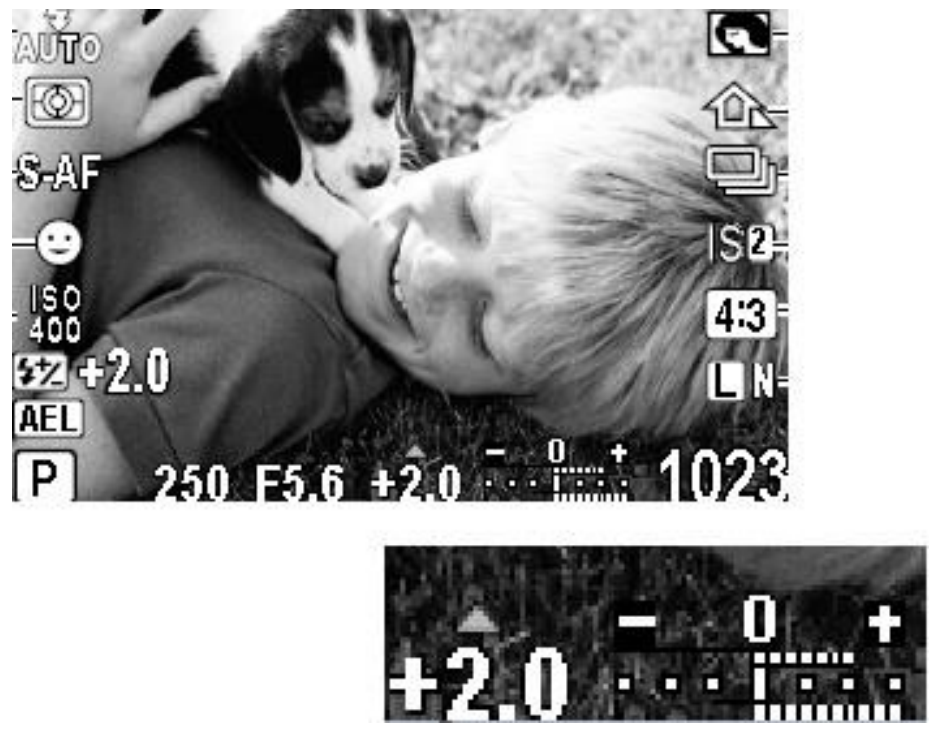

In this example there is a numeric value as well as an indicator on the meter. At the bottom we can see that the desired value is $+2 \mathrm{EV}$ but the measured EV is still $1 \mathrm{EV}$ too high. We can tell that the measured EV is too high, because the lower dotted bar goes out further that the "setting" bar above it. The center where the 0 is, is what we would consider a "normal" picture.

44) You must answer this question correctly to move on. If you answer incorrectly, the question will be reset.

What do you call:

The amount of light allowed to reach the film or sensor
( ) Exposure
( ) ISO setting
( ) Depth of Field
( ) Aperture
( ) Shutter
( ) F-stop

45) Your previous answer was incorrect, please go over this section again and try again. Attempt \#2.

What do you call:

The amount of light allowed to reach the film or sensor 

( ) Exposure
( ) ISO setting
( ) Depth of Field
( ) Aperture
( ) Shutter
( ) F-stop
Correct!

\section{Letting light in}

Letting light in:

Now that we know about exposure, we now want to know how to change the amount of light we let in. Why would we want to know this? Well even if we are setting the exposure value and letting the automatic system pick how to obtain the amount of light wanted, it does not mean it will do it the proper way. There are many ways to increase the amount of light we let in, and each one has consequences in the way the picture will look. The most basic ways we can change the amount of light we let in are with aperture, shutter speed, the ISO setting and the flash.

When changing settings manually, there are 4 options on top of the auto mode. Automatic settings are usually designated by "auto". As in all other modes, ISO can always be changed manually or left to be chosen automatically.

"P" allows you to change the exposure value (which is always at 0 by default), but the camera sets the aperture and shutter speed.

"A" allows you to change the exposure value and aperture $\backslash f$-stop, but the shutter is set automatically based on the EV and f-stop you chose.

"S" allows you to change the exposure value and shutter speed, but the aperture is set automatically based on the EV and shutter speed you chose. Finally, "M" allows you change everything manually, except for the EV since shutter speed and aperture are now manual.

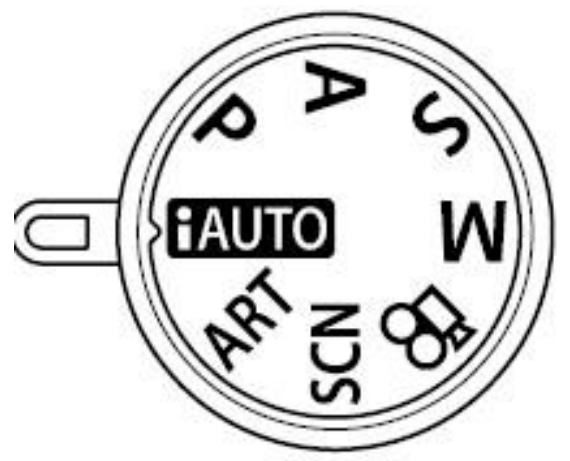

Before answering the question, please proceed to the bottom of the page where the 3D model will have loaded. Select the task on the right side of the box, and follow the steps. You can repeat a task if you want by clicking on it. 
46) You must answer this question correctly to move on. If you answer incorrectly, the question will be reset.

What setting does not allow you to change the exposure value directly

( ) $\mathrm{P}$

( ) $\mathrm{S}$

( ) A

( ) $\mathrm{M}$

47) Your previous answer was incorrect, please go over this section again and try again. Attempt \#2.

What setting does not allow you to change the exposure value directly
( ) $\mathrm{P}$
( ) $\mathrm{S}$
( ) A
( ) $\mathrm{M}$

Correct!

\section{Flash}

Changing settings:

Flash:

We will start with the flash because it is both the easiest and most complicated. It is the easiest because most cameras have an onboard flash which will brighten the center of your picture, but there are many situations when you can't use a flash and there are so many external flashes and ways to use them that going over that would be twice as long as this entire tutorial. When you have things in the way (such as snow, rain, glass) the flash will be diffracted and reflected and ruin the picture (you will see almost nothing). There is also the problem that most flashes are "red eye" flashes and distract people who then try to pose and move away before the picture is even over. Once you use a flash once, the jig is up, everyone knows you are there and those candid moments are gone. Lastly, many situations can't use a flash such as anything further than 15 feet ( 5 meters), wildlife, museums, concerts, small animals or infants or when you want more than the center of your picture to be properly lit. If you must, you can use it, but try to exhaust the possibilities we will be exploring first. If you are using it, know that you can change the flash strength in EV's.

\section{Shutter speed}

Shutter speed and exposure time: 
Shutter speed is probably the next best known concept after the flash. The shutter is what covers the sensor before and after the picture is taken. The shutter speed (also known as exposure time) refers to the amount of time the shutter remains open to let light in. Although you can have shutters speeds in the realm of seconds, shutter speed is usually expressed in fractions. For example, instead of saying 0.002 seconds, it will be $1 \backslash 500$, which shows up simply as "500" in the camera. When you double the amount of time the shutter remains open (so going from $1 \backslash 500$ to $1 \backslash 250$ for example), you get an extra EV. When you half the amount of time the shutter remains open (so make it twice as fast, such as going from $1 \backslash 500$ to $1 \backslash 1000$ ), you get one EV less. The effect of playing with shutter speed is that you can obtain sharp images at high shutter speeds. The negative effect is that if you have a shutter speed that is too slow, 30 for example, you risk getting unwanted blurriness from your hands shaking or the movements of people if you are trying to get a still shot.

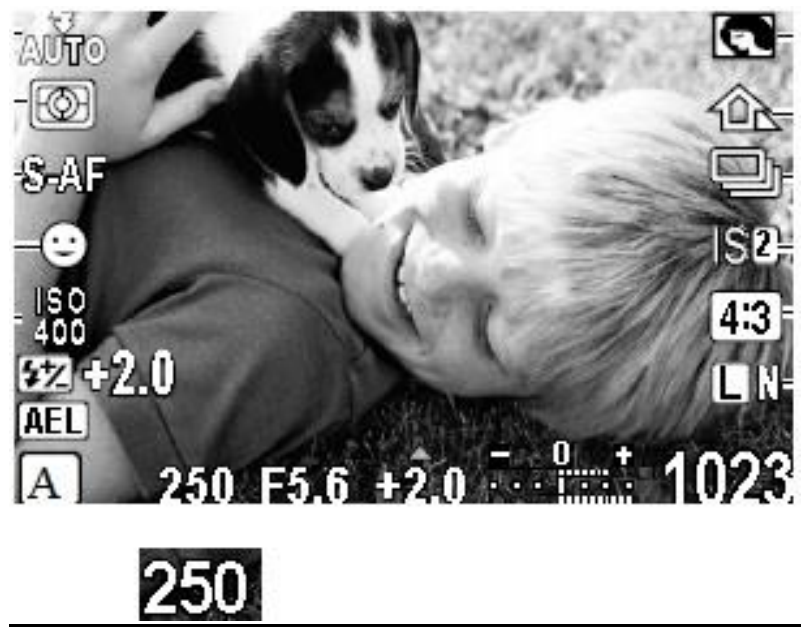

Here we can see that the shutter speed is displayed as 250 , meaning it stays open for $1 / 250$ of a second.

Before answering the question, please proceed to the bottom of the page where the 3D model will have loaded. Select the task on the right side of the box, and follow the steps. You can repeat a task if you want by clicking on it.

48) You must answer this question correctly to move on. If you answer incorrectly, the question will be reset.

What do you call:

Cover that controls the amount of time light reaches the sensor $\backslash$ film

( ) Exposure

( ) ISO setting

( ) Depth of Field

( ) Aperture

( ) Shutter 
( ) F-stop

49) Your previous answer was incorrect, please go over this section again and try again. Attempt \#2.

What do you call:

Cover that controls the amount of time light reaches the sensor $\backslash$ film

( ) Exposure

( ) ISO setting

( ) Depth of Field

( ) Aperture

( ) Shutter

( ) F-stop

Correct!

\section{Aperture}

Aperture (size of the opening) and depth of field:

Aperture, which is measured in f-stops, refers to the size of the opening in the lens. The opening in the lens is again measured as a fraction of $1 \backslash \#$, but is normally referred to as $\mathrm{f} \#$ and simply displayed as a number on the camera. Unfortunately, the f-stop values are not as simple to convert to their effect on the EV. The scale is nonlinear, but a change of one stop is equivalent to $1 \mathrm{EV}$. One stop refers to the transition between an f-stop value of 1.4 to 2,2 to $2.8,2.8$ to 4,4 to $5.6,5.6$ to 8,8 to 11,11 to 16 and more. Since most people won't memorize this, the important thing to retain is that most cameras change in $1 \backslash 3,1 \backslash 2$ or in full stop and that increasing the number means a smaller opening (and as such less light coming in). If there were no other effects than the amount of light, it would be obvious to simply leave it open at max all the time.

However, changing the aperture changes the depth of field (DOF). The depth of field literally refers to how deep things are in focus (eg. if you have a DOF of $1 \mathrm{~m}$, you will have blur in front, then 1 meter of in-focus objects, then more blur). This blurriness of the front and back of the picture is called "Gaussian blur". Most people recognize this when the object or person is in focus, but the background is not. This is a very sought-after effect but sometimes is not appropriate. If you want things to be in focus at different distances, you will want a greater DOF. So, the smaller the f-stop value, the smaller the DOF and the larger the opening in the lens. 


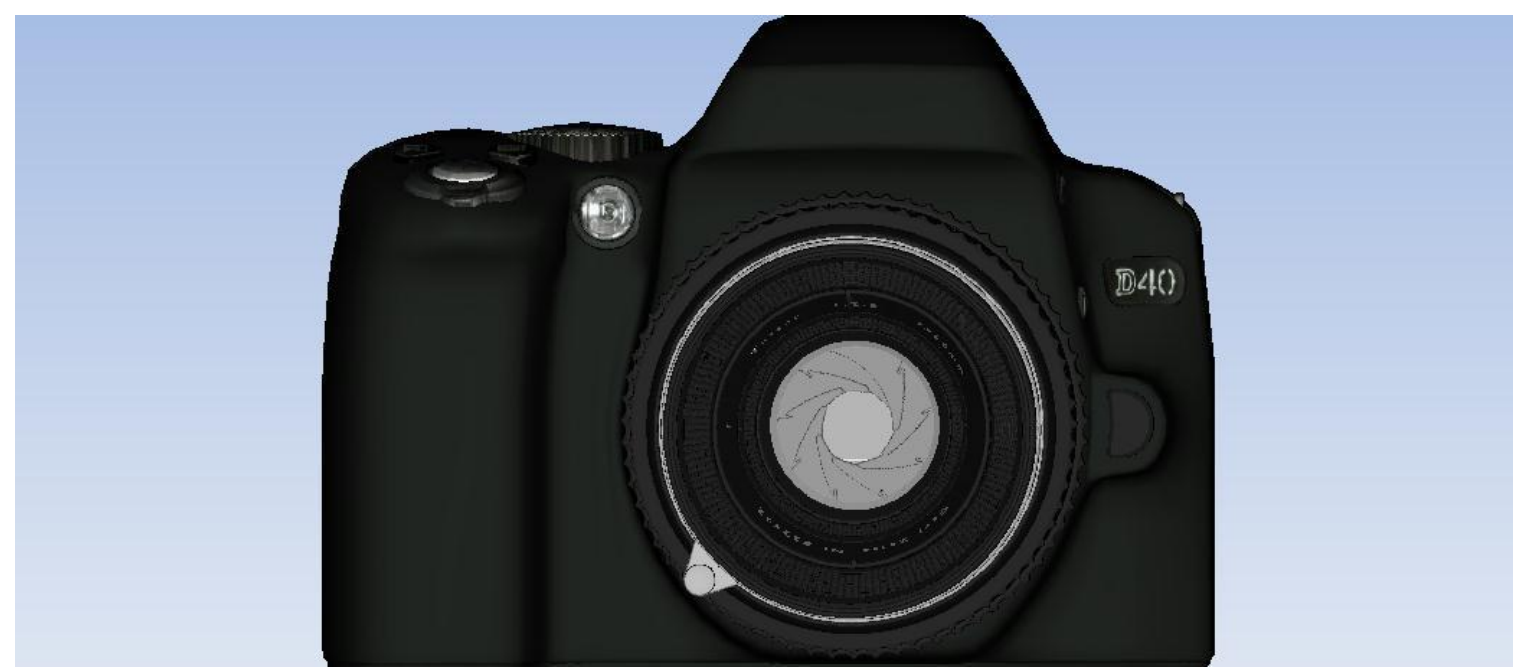

Here we can see that the iris is slightly open. This represents a F-Stop of about 7.1

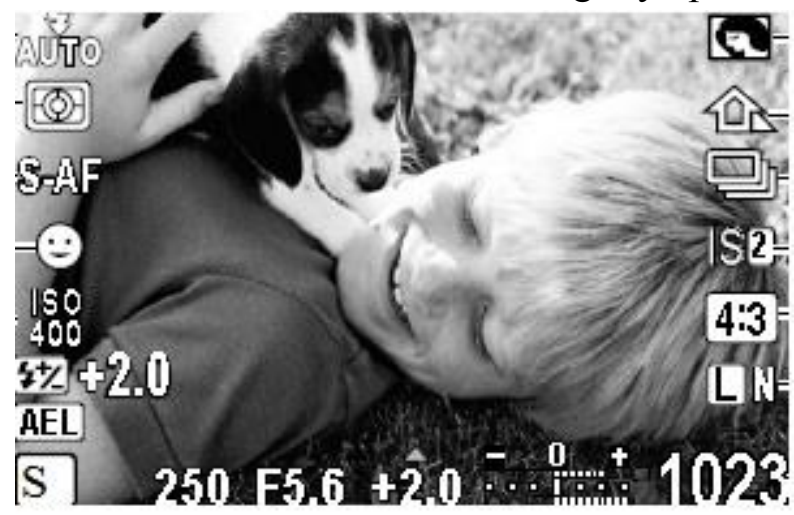

\section{F5.6}

Here we can see that the F-Stop has been set to 5.6, or F5.6. As a medium opening size, it will have a fairly large depth of field.

Before answering the question, please proceed to the bottom of the page where the 3D model will have loaded. Select the task on the right side of the box, and follow the steps. You can repeat a task if you want by clicking on it.

50) You must answer this question correctly to move on. If you answer incorrectly, the question will be reset.

What do you call:

A measure of the aperture

( ) Exposure

( ) ISO setting

( ) Depth of Field

( ) Aperture

( ) Shutter 
( ) F-stop

51) Your previous answer was incorrect, please go over this section again and try again. Attempt \#2.

What do you call:

A measure of the aperture

( ) Exposure

( ) ISO setting

( ) Depth of Field

( ) Aperture

( ) Shutter

( ) F-stop

Correct!

\section{ISO}

ISO:

ISO setting, also called ISO speed, refers to the sensitivity of the sensor. Each time you double your ISO setting, you increase your EV by 1 . The default setting is 100 for almost all digital cameras. The downside of increasing the sensitivity is that by amplifying the signal, you get signal noise or grain. This is not something you hear, but artefacts and graininess in the image. The trade-off here is quite simple, a larger number means brighter pictures but also more noise.

In order to change the ISO speed, you first turn the top dial to any setting. The next step is to use the buttons on the back of the camera. Once ISO speed is selected in the menu, you can change it.

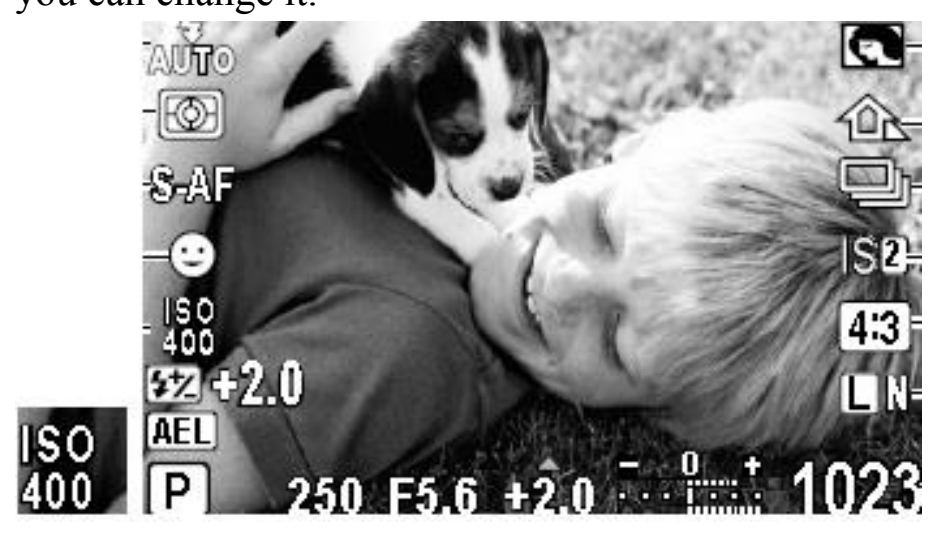

52) You must answer this question correctly to move on. If you answer incorrectly, the question will be reset. 
What do you call:

A measure to the sensitivity of the film or sensor to light

( ) Exposure

( ) ISO setting

( ) Depth of Field

( ) Aperture

( ) Shutter

( ) F-stop

53) Your previous answer was incorrect, please go over this section again and try again. Attempt \#2.

What do you call:

A measure to the sensitivity of the film or sensor to light

( ) Exposure

( ) ISO setting

( ) Depth of Field

( ) Aperture

( ) Shutter

( ) F-stop

Correct!

\section{Tutorial Completed}

Thank you, you have now completed the tutorial section and will now begin the second quiz phase. 


\section{Appendix D}

\section{Opinion Questions}

What did you think

As you answer these last questions, please feel free to leave comments in the comment boxes. Please only write comments about the question being asked.

Did you think that the 3D model helped you learn better?

() Yes

( ) $\mathrm{No}$

Comments:

Did you think that viewing the video helped you learn better?

( ) Yes

( ) No

Comments:

Do you think that having a 3D interactive model of a camera that showed how the camera works like the video did, but allowed you to interact with it, would have helped you learn better?

( ) Yes

( ) No

Comments:

Was viewing the video more motivating than reading the text?

( ) Yes

( ) $\mathrm{No}$

Comments: 
Do you think using a 3D interactive model would be more motivating than viewing the video?

( ) Yes

( ) No

Comments:

Did you enjoy using the video?

( ) Yes

( ) No

Comments:

Do you think that the animation helped you learn as much as a 3D interactive model could have?

() Yes

( ) No

Comments:

Do you think that having a 3D interactive model of a camera that showed how the camera works would have helped you learn better?

( ) Yes

( ) No

Comments:

Was using the 3D model more motivating than reading the text?

() Yes

( ) $\mathrm{No}$

Comments: 
Do you think using a 3D model would be more motivating than reading the text?

( ) Yes

( ) No

Comments:

Did you enjoy using the 3D model?

() Yes

( ) No

Comments:

Would you want to use a 3D model again in the future?
( ) Yes
( ) No

Comments:

Do you think that an animation would help you learn as much as a 3D interactive model?

( ) Yes

( ) No

Comments:

Did you have any difficulty understanding some of the questions or explanations?

() Yes

( ) No

Is english your first language?

( ) Yes 

( ) No
Is English your second language?
() Yes
( ) No
How fluent are you in english?
( ) Fully fluent
( ) I can manage
( ) Not fluent 


\section{Bibliography}

Adesope, O. O., \& Nesbit, J. C. (2012). Verbal redundancy in multimedia learning environments: A meta-analysis. Journal of Educational Psychology, 104(1), 250263. doi: $10.1037 / \mathrm{a} 0026147$

Allison, P. D. (1990). Change Scores as Dependent Variables in Regression Analysis. Sociological Methodology, 20, 93-114.

Arguel, A., \& Jamet, E. (2009). Using video and static pictures to improve learning of procedural contents. Computers in Human Behavior, 25(2), 354-359. doi:10.1016/j.chb.2008.12.014

Ashby, F. G., \& Gott, R. E. (1988, January). Decision rules in the perception and categorization of multidimensional stimuli. Journal of experimental psychology. Learning, memory, and cognition. Retrieved from http://www.ncbi.nlm.nih.gov/pubmed/2963894

Beaunieux, H., Hubert, V., Witkowski, T., Pitel, A.-L., Rossi, S., Danion, J.-M., ... Eustache, F. (2006). Which processes are involved in cognitive procedural learning? Memory (Hove, England), 14(5), 521-39. doi:10.1080/09658210500477766

Bisanz, J., \& LeFevre, J. (1990). Strategic and nonstrategic processing in the development of mathematical cognition. In D. F. Bjorklund (Ed.), Children's Strategies: Contemporary Views of Cognitive Development (pp. 213-244). Hillsdale, NJ: Earlbaum.

Bruner, J. S., Goodnow, J. J., \& Austin, G. A. (1986). Study of Thinking (p. 330). Transaction Publishers. Retrieved from http://books.google.com/books?id=xDZlQgt-xa0C\&pgis=1

Brunye, T., Taylor, H. A., \& Rapp, D. N. (2008). Repetition and Dual Coding in Procedural Multimedia Presentations. Applied Cognitive Psychology, 895(September 2007), 877-895. doi:10.1002/acp

Catrambone, R., \& Holyoak, K. J. (1989). Overcoming Contextual Limitations on Problem-Solving Transfer. Journal of Experimental Psychology, 6, 1147-1156.

ChanLin, L. (1996). Enhancing Computer Graphics Through Metaphorical Elaboration. Journal Of Instructional Psycholog, 23(3), 196-205.

ChanLin, L. (1998). Animation to teach students of different knowledge levels. Journal of Instructional Psychology, 25(3), 166-187. 
Chin-Parker, S., \& Ross, B. H. (2002). The effect of category learning on sensitivity to within-category correlations. Memory \& cognition, 30(3), 353-62. Retrieved from http://www.ncbi.nlm.nih.gov/pubmed/12061756

Cohen, N. J., \& Squire, L. R. (1980). Preserved Learning and Retention of PatternAnalyzing Skill in Amnesia : Dissociation of Knowing How and Knowing that. Science, 210(4466), 207-210.

DeStefano, D., \& LeFevre, J.-A. (2007). Cognitive load in hypertext reading: A review. Computers in Human Behavior, 23(3), 1616-1641. doi:10.1016/j.chb.2005.08.012

Edwards, J. R. (2001). Ten Difference Score Myths. Organizational Research Methods, 4(3), 265-287. doi:10.1177/109442810143005

Eveland, W. P., Marton, K., \& Seo, M. (2004). Moving beyond "Just the Facts": The Influence of Online News on the Content and Structure of Public Affairs Knowledge. Communication Research, 31(1), 82-108. doi:10.1177/0093650203260203

Eveland, Wi. P., \& Dunwoody, S. (2001). User Control and Structural Isomorphism or Disorientation and Cognitive Load?: Learning From the Web Versus Print. Communication Research, 28(1), 48-78. doi:10.1177/009365001028001002

Ferguson, E. S. (1977). The Mind ' s Eye : Nonverbal Thought in Technology. Science, 197(4306), 827-836.

Fiore, S. M., Cuevas, H. M., \& Oser, R. L. (2003). A picture is worth a thousand connections: the facilitative effects of diagrams on mental model development and task performance. Computers in Human Behavior, 19(2), 185-199. doi:10.1016/S0747-5632(02)00054-7

Gentner, D., Loewenstein, J., \& Thompson, L. (2003). Learning and transfer: A general role for analogical encoding. Journal of Educational Psychology, 95(2), 393-405. doi:10.1037/0022-0663.95.2.393

Glenberg, A. M., \& Langston, W. E. (1992). Comprehension of illustrated text: Pictures help to build mental models. Journal of Memory and Language, 31(2), 129-151. doi:10.1016/0749-596X(92)90008-L

Gregory Ashby, F., \& Crossley, M. J. (2010). Interactions between declarative and procedural-learning categorizatoin systems. Neurobiology of learning and memory, 94, 1-12.

Hallett, D., Nunes, T., \& Bryant, P. (2010). Individual differences in conceptual and procedural knowledge when learning fractions. Journal of Educational Psychology, 102(2), 395-406. doi:10.1037/a0017486 
Hasler, B. S., Kersten, B., \& Sweller, J. (2007). Learner Control , Cognitive Load and Instructional Animation. Applied Cognitive Psychology, 21, 713-729. doi:10.1002/acp

Hegarty, M., Kriz, S., \& Cate, C. (2003). The Roles of Mental Animations and External Animations in Understanding Mechanical Systems. Cognition and Instruction, 21(4), 325-360.

Hiebert, J., \& Lefevre, J.-A. (1986). Conceptual and procedural knowledge in mathematics: An introductory Analysis. In Conceptual and Procedural Knowledge: The case of Mathematics (pp. 1-27). Hillsdale, NJ: Erlbaum.

Hoffman, A. B., \& Rehder, B. (2010). The costs of supervised classification: The effect of learning task on conceptual flexibility. Journal of experimental psychology. General, 139(2), 319-40. doi:10.1037/a0019042

Kalyuga, S., Chandler, P., \& Sweller, J. (1999). Managing Split-attention and Redundancy in Multimedia Instruction. Applied Cognitive Psychology, 13, 351-371.

Kurtz, K. J., Miao, C., \& Gentner, D. (2001). Learning by Analogical Bootstrapping. Journal of the Learning Sciences, 10(4), 417-446.

Kutner, M. H., Nachtsheim, C. J., Neter, J., \& Li, W. (2005). Applied Linear Statistical Models. (B. Gordon, R. T. Hercher, \& L. Stone, Eds.) (Fifth., p. 1396). New York: McGraw-Hill Irwin.

Loewenstein, J., \& Gentner, D. (2001). Spatial Mapping in Preschoolers : Close Comparisons Facilitate Far Mappings. Journal of Cognition and Development, 2(2), 189-219.

Mayer, R. E., \& Anderson, R. B. (1992). The Instructive Animation: Helping Students Build Connections Between Words and Pictures in Multimedia Learning. Journal of Educational Psychology, 84(4), 444-452.

Mayer, R. E., Hegarty, M., Mayer, S., \& Campbell, J. (2005). When static media promote active learning: annotated illustrations versus narrated animations in multimedia instruction. Journal of experimental psychology. Applied, 11(4), 256-65. doi:10.1037/1076-898X.11.4.256

Mayer, R. E., \& Johnson, C. I. (2008). Revising the redundancy principle in multimedia learning. Journal of Educational Psychology, 100(2), 380-386. doi:10.1037/00220663.100.2.380

Moreno, R., \& Valdez, A. (2005). Cognitive Load and Learning Effects of Having Students Organize Pictures and Words in Multimedia Environments : The Role of 
Student Interactivity and Feedback. Educational Technology Research and Development, 53(3), 35-45.

NGRAIN. (2012a). NGRAIN Producer Pro. Vancouver, BC. Retrieved from http://www.ngrain.com/software/producer/

NGRAIN. (2012b). NGRAIN Viewer. Vancouver, BC. Retrieved from http://www.ngrain.com/software/viewer/

Oakes, L. M., \& Ribar, R. J. (2005). A Comparison of Infants' Categorization in Paired and Successive Presentation Familiarization Tasks. Infancy, 7(1), 85-98.

Park, O., \& Gittelman, S. S. (1992). Selective Use of Animation and Feedback in Computer-Based Instruction. Educational Technology Research and Development, 40(4), 27-38.

Poldrack, R. a, \& Foerde, K. (2008). Category learning and the memory systems debate. Neuroscience and biobehavioral reviews, 32(2), 197-205.

doi:10.1016/j.neubiorev.2007.07.007

Reid, D. J., \& Beveridge, M. (1990). Reading Illustrated Science Texts: a MicroComputer Based Investigation of Children'S Strategies. British Journal of Educational Psychology, 60(1), 76-87. doi:10.1111/j.2044-8279.1990.tb00923.x

Rieber, L. P. (1990). Using computer animated graphics with science instruction with children. Journal of Educational Psychology, 82(1), 135-140.

Rieber, L. P. (1991). Animation, incidental learning, and continuing motivation. Journal of Educational Psychology, 83(3), 318-328.

Rieber, L. P. (1996). Animation as feedback in a computer-based simulation:

Representation matters. Educational Technology Research and Development, 44(1), 5-22. doi:10.1007/BF02300323

Rittle-Johnson, B., \& Star, J. R. (2007). Does comparing solution methods facilitate conceptual and procedural knowledge? An experimental study on learning to solve equations. Journal of Educational Psychology, 99(3), 561-574. doi:10.1037/00220663.99.3.561

Ruiz, J. G., Cook, D. a, \& Levinson, A. J. (2009). Computer animations in medical education: a critical literature review. Medical education, 43(9), 838-46. doi:10.1111/j.1365-2923.2009.03429.x

Squire, L. R. (2004). Memory systems of the brain: a brief history and current perspective. Neurobiology of learning and memory, 82(3), 171-7. doi:10.1016/j.nlm.2004.06.005 
Star, J. R., \& Rittle-Johnson, B. (2009). It pays to compare: An experimental study on computational estimation. Journal of Experimental Child Psychology, 102, 408-426.

SurveyGizmo. (2013). SurveyGizmo. Boulder, CO: Widgix. Retrieved from https://students.sgizmo.com

Tewksbury, D., \& Althaus, S. L. (2000). Differences in Knowledge Acquisition Among Readers of the Paper and Online Versions of a National Newspaper. Journalism \& Mass Communication Quarterly, 77(3), 457-479. doi:10.1177/107769900007700301

Tunney, N., Taylor, L., Higbie, E., \& Haist, F. (2001). Declarative Memory and Motor Learning in the Older Adult. Physical \& Occupational Therapy In Geriatrics, 20(2), 21-42. doi:10.1300/J148v20n02_02

Tversky, B., Bauer, J., \& Betrancourt, M. (2002). Animation : can it facilitate? International Journal of Human-Computer Studies, 57, 247-262. doi:10.1006/ijhc. 1017

Vakil, E., Hoffman, Y., \& Myzliek, D. (1998). Active Versus Passive Procedural Lear ning in Older and Younger Adults. Neuropsychological Rehabilitation, 8(1), 31-41.

Yeung, A., Jin, P., \& Sweller, J. (1998). Cognitive Load and Learner Expertise: SplitAttention and Redundancy Effects in Reading with Explanatory Notes. Contemporary educational psychology, 23(1), 1-21. Retrieved from http://www.ncbi.nlm.nih.gov/pubmed/9514686

YouTube, L. (2013). YouTube. Retrieved September 01, 2012, from http://www.youtube.com/ 